\title{
Conforto térmico em ambientes de internação hospitalar naturalmente ventilados
}

\author{
Thermal comfort in naturally ventilated patient rooms
}

\begin{abstract}
Bianca Milani de Quadros
Martin Ordenes Mizgier

Resumo

A

ventilação natural pode ser utilizada em ambientes hospitalares com baixo risco de infecção, especialmente em regiões de clima quente e úmido, como é o caso da cidade de Florianópolis, SC. Embora existam evidências que comprovem a influência positiva da ventilação na recuperação de pacientes, a norma brasileira RDC 50 recomenda fortemente o uso de sistemas de condicionamento artificial. O objetivo da pesquisa foi avaliar o conforto térmico em quartos de internação hospitalar com distintas formas de ventilação natural. A pesquisa foi realizada por meio de simulações computacionais em dinâmica de fluidos (CFD) para três tipologias de quartos de internação: com ventilação unilateral simples, com ventilação unilateral dupla e com ventilação cruzada. Analisou-se o desempenho da ventilação em um dia típico do verão e em um dia típico da primavera, com ventos norte e nordeste de $1,0 \mathrm{~m} / \mathrm{s}$, $3,0 \mathrm{~m} / \mathrm{s}$ e $6,0 \mathrm{~m} / \mathrm{s}$. Os resultados demonstram melhor desempenho da ventilação unilateral dupla e da ventilação cruzada em comparação à ventilação unilateral simples, esta amplamente utilizada em quartos para internação. Uma vez que a tendência de hospitais verticalizados e densos dificulta a adoção da ventilação cruzada, conclui-se que os projetos arquitetônicos de ambientes de internação hospitalar devem considerar a ventilação unilateral dupla como uma alternativa eficiente para o conforto térmico.

Palavras-chave: Arquitetura hospitalar. Ventilação natural. Conforto térmico. Simulação CFD.

Abstract

Natural ventilation can be an interesting passive cooling strategy for hospital rooms with a low infection risk, especially in a hot and humid climate like in the city of Florianópolis in south Brazil. Although there is enough evidence to prove the positive influence of natural ventilation on patients' healing, the Brazilian standard RDC50, on technical practices for hospital building projects, strongly recommends the use of HVAC systems for these rooms. Thus, the main purpose of this study is to evaluate thermal comfort in patient rooms using different configurations of natural ventilation. The methodology is based on CFD

${ }^{1}$ Bianca Milani de Quadros ${ }^{1}$ Universidade do Sul de Santa Catarina Florianópolis - SC - Brasil

${ }^{2}$ Martin Ordenes Mizgier ${ }^{2}$ Universidade Federal de Santa Catarina Florianópolis - SC - Brasil

Recebido em 30/01/19

simulation for three configurations of natural ventilation in a basic patient room: single-sided ventilation, double single-sided ventilation and cross-ventilation. The thermal performance of each natural ventilation configuration is analysed for a typical summer day and a typical spring day, with wind coming from the north and northeast directions at three different speed levels: $1.0 \mathrm{~m} / \mathrm{s}, 3.0 \mathrm{~m} / \mathrm{s}$ and $6.0 \mathrm{~m} / \mathrm{s}$. The results show an overall higher ventilation performance for the double singlesided ventilation and for cross-ventilation. The trend to verticalise and densify hospital buildings makes it difficult to adopt cross-ventilation. Therefore, the conclusion of the study is that double single-sided ventilation should be considered as an effective alternative to achieve thermal comfort in patient rooms.
\end{abstract} Aceito em 14/04/19
Keywords: Hospital architecture. Natural ventilation. Thermal comfort. CFD simulation. 


\section{Introdução}

No início do século XIX a enfermeira britânica Florence Nightingale, fundadora da enfermagem moderna, já sugeria que os problemas dos hospitais consistiam na falta de padrões adequados de iluminação e de ventilação natural, na não observância de áreas mínimas por leito e na superlotação por pacientes (MIQUELIN, 1992). No entanto, apenas no final do século XX iniciam-se as discussões sobre a necessidade do planejamento de espaços com foco no usuário dos hospitais (TOLEDO, 2006).

Pesquisas recentes têm apresentado um conjunto de evidências que comprovam a influência do espaço arquitetônico na recuperação dos pacientes internados. Os estudos de Dilani (2005) e de Ulrich et al. (2004) encontraram relação positiva entre a aplicação de conceitos de conforto ambiental e a recuperação de pacientes. Para Dilani (2005), a adoção de estratégias de conforto ambiental e humanização em hospitais resulta em recuperações mais rápidas, em menores custos com medicamentos, na redução da solicitação de apoio de enfermagem e na elevação da moral dos profissionais da saúde. Como consequência, há aumento da produtividade e diminuição dos custos das internações (DILANI, 2005; ULRICH et al., 2004).

De acordo com Salonen et al. (2013), há evidência de que os seguintes fatores físicos do ambiente interno afetam a saúde e o bem-estar dos pacientes: segurança, conforto térmico, conforto acústico, leiaute e tipologia do quarto, janelas (luz natural e visão do exterior), natureza e jardim, iluminação, cores, acabamento do piso, ergonomia dos mobiliários, sinalização, obras de arte e música.

Com relação ao conforto térmico em hospitais brasileiros, a Resolução RDC 50 (AGÊNCIA..., 2002) recomenda o uso de sistemas de condicionamento artificial, com a alegação de que ele é necessário para promover maior conforto térmico aos pacientes, manter estáveis as condições de pressão, controlar riscos de doenças transmitidas pelo ar e preservar a qualidade dos medicamentos armazenados. No entanto, edifícios condicionados artificialmente apresentam grande impacto ambiental, requerem maiores custos com manutenção e operação, e aumentam a sensação de enclausuramento e de desconexão com o ambiente externo (JONES; WEST, 2001).

A ventilação natural tem sido considerada uma alternativa vantajosa a ser implantada em estabelecimentos assistenciais a saúde com risco de infecção hospitalar baixo, considerados áreas não críticas. Além de reduzir o custo ao longo de todo o ciclo de vida do hospital, Escombe et al. (2007) e Levin (2011) afirmam que a ventilação natural pode reduzir o risco de infecção hospitalar, mas ainda há necessidade de estudos epidemiológicos para quantificar a taxa de renovação do ar necessária.

No entanto, há limitação na aplicação da ventilação natural em áreas críticas, como salas cirúrgicas, UTI e central de materiais esterilizados. Nesses ambientes existe risco maior de desenvolvimento de infecções relacionadas à assistência médica, seja pela execução de que envolvem artigos críticos ou material biológico, seja pela realização de procedimentos invasivos ou pela presença de pacientes com suscetibilidade aumentada aos agentes infecciosos. Para maior controle, a climatização artificial deve garantir estabilidade nas condições higrotérmicas (temperatura do ar, umidade relativa do ar e número de renovações do ar por hora), fazer uso de filtros do tipo Hepa e contar com a manutenção e a limpeza constante do sistema.

Segundo a Organização Mundial da Saúde (ORGANIZAÇÃO..., 2009), a decisão entre o uso de condicionamento artificial e o natural em áreas hospitalares não críticas deve considerar as condições climáticas locais. Climas com temperaturas extremas durante longo período do ano não podem depender unicamente de estratégias passivas. Já para Lomas e Ji (2009), a ventilação natural pode garantir o conforto térmico dos pacientes em ambientes de internação geral e enfermarias, sendo uma opção interessante nos projetos de novos edifícios hospitalares pautados sob a ótica do conforto ambiental e da eficiência energética.

Nesse sentido, levanta-se uma questão crucial para o desenvolvimento de edifícios hospitalares: a ventilação natural é capaz de garantir o conforto térmico dos usuários de quartos de internação? Para ajudar a responder a essa questão, a presente pesquisa avalia o conforto térmico em quartos de internação hospitalar com distintas formas de ventilação natural.

\section{Referencial teórico}

Em suas origens, os hospitais eram locais procurados por pacientes para morrer com um mínimo de dignidade (GÓES, 2004). A estrutura do hospital tinha a função de segregar e excluir os enfermos, loucos, devassos e prostitutas da sociedade, para minimizar riscos de epidemias e prestar assistência social. Somente a partir do século XVIII surge a noção do hospital como local de cura pela prática da medicina (TOLEDO, 2006). Essa mudança de conceito fez emergir questionamentos sobre os procedimentos médicos e as edificações em que 
essas atividades são praticadas, com foco na pesquisa sobre a tipologia dos hospitais (FOUCAULT, 1979; MIQUELIN, 1992; TOLEDO, 2006).

No final do século XX tem-se início as discussões sobre os aspectos de humanização e de conforto ambiental no projeto arquitetônico de ambientes de saúde. No Brasil os impactos das transformações conceituais da arquitetura hospitalar são visíveis nas obras do arquiteto João Filgueiras Lima, mais conhecido como Lelé. A arquitetura assume papel importante na busca do hospital por este ser uma máquina de curar (TOLEDO, 2006). Dois hospitais da rede Sarah Kubitschek, o de Salvador e o do Rio de Janeiro, se destacam na produção arquitetônica como valiosos exemplares da arquitetura bioclimática. Pesquisas realizadas por meio de ensaios em túnel de vento demonstram que ambos os hospitais apresentam bom desempenho da ventilação natural por meio das coberturas em sheds (LUKIANTCHUKI, 2010).

É sabido que a ventilação natural é uma estratégia importante para a condição de conforto térmico dos ocupantes de uma edificação (RUPP; VÁZQUEZ; LAMBERTS, 2015). Resultados de experimentos de campo realizados em Maceió, AL, mostram que, do ponto de vista da preferência e da aceitabilidade, em ambientes onde a ventilação natural é utilizada como a principal forma de condicionamento, os usuários tendem a indicar frequentemente a preferência por "maior movimento do ar" (CANDIDO et al., 2010).

O desempenho da ventilação natural é um fenômeno complexo de ser modelado devido aos processos termodinâmicos e de escoamento de ar envolvidos no ambiente interno. Atualmente, existem modelos confiáveis desenvolvidos para avaliação da ventilação em edificações, porém sua aplicação se restringe ao âmbito da pesquisa, sem aplicação prática no projeto arquitetônico.

Os modelos variam desde algoritmos empíricos simplificados para o cálculo da taxa de ventilação global até técnicas sofisticadas de fluidodinâmica computacional (CFD) para solucionar equações diferenciais que descrevem o escoamento de fluidos, as chamadas equações de Navier-Stokes. A simulação CFD surgiu em função da indústria aeroespacial nas décadas de 1960 e 1970. No início do século XXI introduziu-se a aplicação dessa ferramenta em estudos de conforto ambiental em edificações (ZHAI, 2006).

Em geral, o fluxo de ar é analisado mediante a distribuição da velocidade do ar, da temperatura, da umidade, da intensidade da turbulência e da concentração de contaminantes (ZHAI, 2006; KOLOKOTRONI, 2007). Os principais aspectos do projeto arquitetônico para a determinação do fluxo de ar no interior das edificações são o tamanho, a forma e a localização das aberturas (CANDIDO; BITTENCOURT, 2006). Ayata e Yildiz (2006) acrescentam que o zoneamento funcional das edificações pode aumentar significativamente o potencial da ventilação natural nos dias quentes de verão em climas moderados.

A configuração das aberturas de um ambiente define sua forma de ventilar. Ambientes ventilados unilateralmente, como o próprio nome indica, apresentam uma ou mais janelas em uma das fachadas somente. A entrada e a saída do ar nesses ambientes podem ocorrer pela ação dos ventos ou mesmo por diferença de temperatura do ar (ALLOCCA; CHEN; GLICKSMAN, 2003; SCHULZE; EICKER, 2013). Em se tratando de uma única abertura, Stabat, Caciolo e Marchio (2012) observaram que o ar quente do ambiente interno sai pela porção superior da abertura, enquanto o ar frio, que vem do ambiente externo, entra pela porção inferior da abertura. Como consequência, existe uma altura na qual o fluxo de ar é invertido, na qual a diferença de pressão é nula, correspondendo ao chamado nível de pressão neutra.

Diversos estudos avaliam o desempenho da ventilação natural das edificações hospitalares. Adamu, Price e Cook (2012) encontraram significante variação na velocidade do ar para as seguintes formas de ventilação adotadas em enfermarias: abertura unilateral simples, abertura unilateral dupla, abertura unilateral com torre de ventilação e abertura unilateral com saída pelo forro. As simulações demonstram que a ventilação natural na enfermaria com abertura unilateral simples foi efetiva apenas até uma profundidade de $3 \mathrm{~m}$. A adição de uma janela, configurando a estratégia da enfermaria como abertura unilateral dupla, resultou em melhorias importantes na taxa de ventilação.

Outros estudos comparativos apontam que a ventilação cruzada resulta em maiores taxas de renovação do ar quando comparada à ventilação unilateral (CHU et al., 2015; AFLAKI; MAHYUDDIN; BAHARUM, 2016). Chenari, Dias Carrilho e Gameiro da Silva (2016) contrariam parcialmente esse resultado ao afirmar que a ventilação cruzada nem sempre apresenta melhor desempenho porque, em ambientes em que a direção do vento não é perpendicular à abertura e em que os ventos apresentam baixa velocidade, os desempenhos da ventilação cruzada e da ventilação unilateral se assemelham.

Ainda dentro da escala do microclima, a localização dos ocupantes nos espaços internos influencia as condições de conforto térmico. Temperatura radiante média e velocidade do ar são as variáveis ambientais que apresentam maiores diferenças de valores de acordo com o ponto em que são medidas. Segundo 
Prajongsan e Sharples (2012), as maiores velocidades do ar estão em áreas localizadas próximas às aberturas de entrada e de saída do ar.

No caso de edificações hospitalares as formas de ventilação natural aplicáveis em quartos de internação são a ventilação unilateral e a cruzada (ORGANIZAÇÃO..., 2009), sendo a primeira a mais usual. A justificativa para a maior adoção da ventilação unilateral em quartos de internação está na localização dos hospitais. Geralmente, os hospitais são implantados em terrenos nos centros urbanos, que demandam edifícios verticalizados e que aproveitam ao máximo a relação entre sua área útil e o número de quartos de internação (MIQUELIN, 1992). A quantidade de quartos é fator primordial para a viabilização de um hospital, o que resulta em tipologias que frequentemente adotam quartos ventilados unilateralmente por proporcionar o melhor aproveitamento da área. A verticalização dos hospitais pode apresentar impacto positivo sobre o tecido urbano, no entanto estudos alertam que vem sendo desconsiderada na legislação urbanística da maioria das cidades brasileiras a relação entre alto gabarito e baixa densidade para a insolação e a ventilação natural na escala da cidade (LIMA; BITTENCOURT, 2017).

\section{Método}

Para avaliar o desempenho de diferentes formas de ventilação natural no conforto térmico em ambientes de internação hospitalar, foram criados casos para simulação CFD que contemplam tipologias típicas de quartos de internação. Os ambientes de internação foram caracterizados com base nos parâmetros estabelecidos pela norma brasileira RDC 50 (AGÊNCIA..., 2002) e pela coleta documental de hospitais da Grande Florianópolis que oferecem internação, a saber: Hospital Nereu Ramos, Maternidade Carmela Dutra, Hospital Universitário Polydoro Ernani de São Thiago (HU/UFSC), Hospital Florianópolis, Hospital Infantil Joana de Gusmão, Hospital Celso Ramos e Unimed Litoral.

Com relação ao clima, as situações de desconforto por calor na cidade de Florianópolis, SC, correspondem a 40\% das 8.760 horas do ano. Após o sombreamento das aberturas, a ventilação natural é a estratégia mais importante para o conforto térmico, com aplicabilidade de $60 \%$ no verão e de $38 \%$ na primavera (PROJETEEE, 2014). No inverno a ventilação natural apresenta aplicabilidade baixa (9\%) para o conforto térmico, tendo maior importância para o atendimento das condições de renovação do ar.

A Figura 1 apresenta a síntese dos modelos simulados: quartos com ventilação unilateral simples (VU1), ventilação unilateral dupla (VU2) e ventilação cruzada (VC). Com relação ao clima, as simulações representam os períodos verão e primavera por apresentarem a ventilação natural como uma das principais estratégias para o conforto térmico em Florianópolis. Os ventos adotados são o norte e nordeste, com três intensidades: alta (6 m/s), média (3 m/s) e baixa (1 m/s). A combinação desses modelos totaliza 36 simulações.

\section{Edificação e clima}

A arquitetura hospitalar tem papel fundamental para a criação de espaços que auxiliem no processo de cura dos pacientes. Por essa razão, foram definidos ambientes de internação como os casos de estudo desta pesquisa.

\section{Caso-base}

O caso-base é caracterizado de acordo com os parâmetros estabelecidos pela norma brasileira RDC 50 (AGÊNCIA..., 2002). Quartos semiprivativos devem dispor de dois leitos para os pacientes, duas poltronas para acompanhantes e outros equipamentos, como escada com dois degraus e mesa para refeição. De acordo com o Sistema de Apoio à Elaboração de Projetos de Investimentos em Saúde (BRASIL, 2013), as dimensões necessárias por leito são de 3,60x3,60 m, medida ampliada para 7,20x3,60 m no caso de dois leitos. Sendo assim, a área útil das unidades de internação modeladas é de 25,92 $\mathrm{m}^{2}$. O pé-direito considerado é o de 3,20 $\mathrm{m}$ de piso a piso, sendo a altura livre de piso a teto de 2,80 m.

Com relação à estratégia de ventilação, o caso-base apresenta ventilação unilateral (VU1). A dimensão da abertura atende ao código de obras do município de Florianópolis, que estabelece uma área mínima de abertura para iluminação e ventilação em hospitais (área de janela de um sexto da área total do ambiente com abertura de 50\%). Assim, o caso-base apresenta uma única janela de correr, de 3,40x1,20 m, com 1,00 m de peitoril e $50 \%$ de abertura (Figura 2). 
Figura 1 - Síntese dos modelos simulados

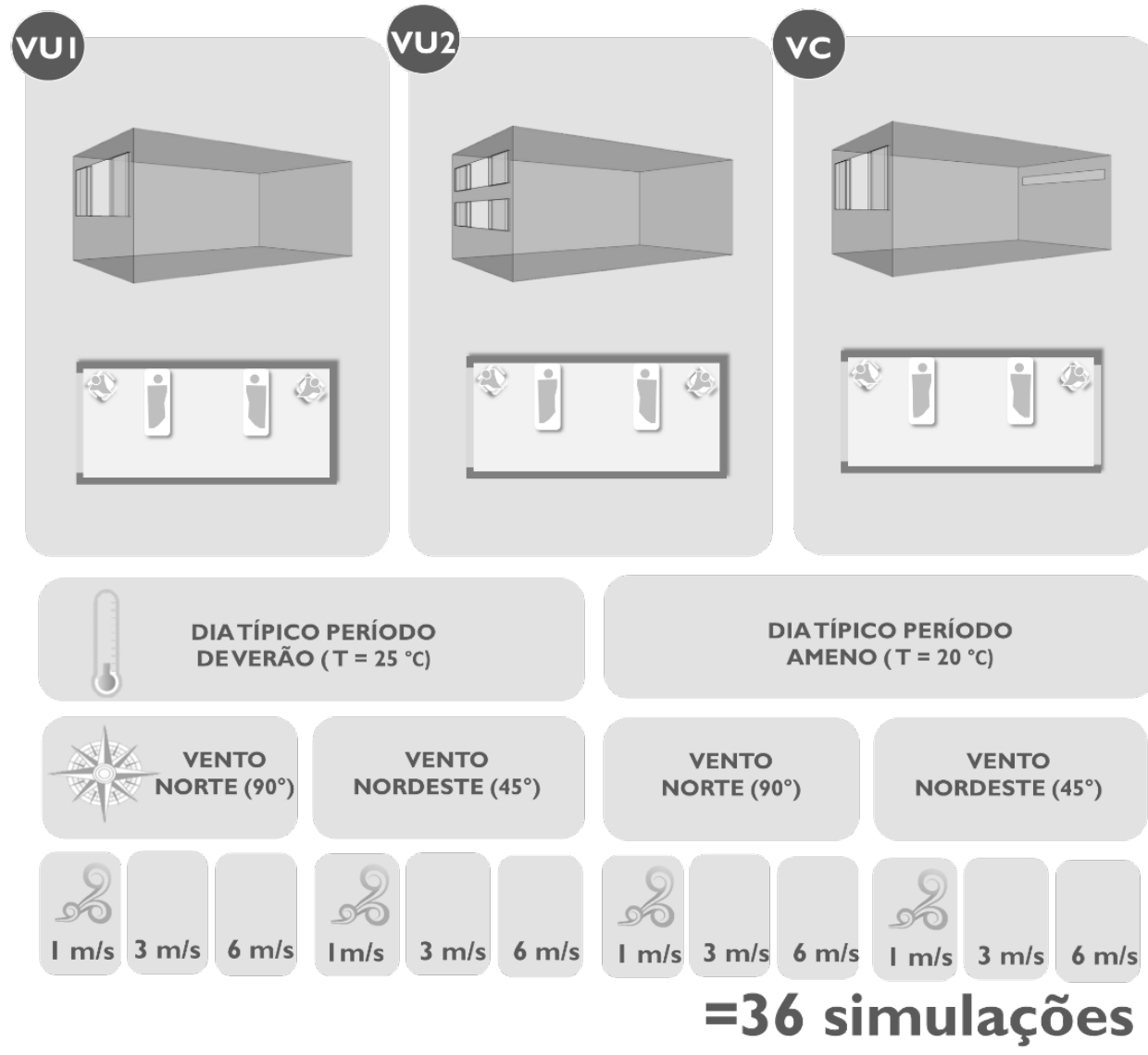

Onde, VUI é ventilação unilateral simples, VU2 é ventilação unilateral dupla, VC é ventilação cruzada e T é temperatura do ar.

Figura 2 - Quartos de internação investigados: quarto com ventilação unilateral simples (VU1), com ventilação unilateral dupla (VU2) e com ventilação cruzada (VC)
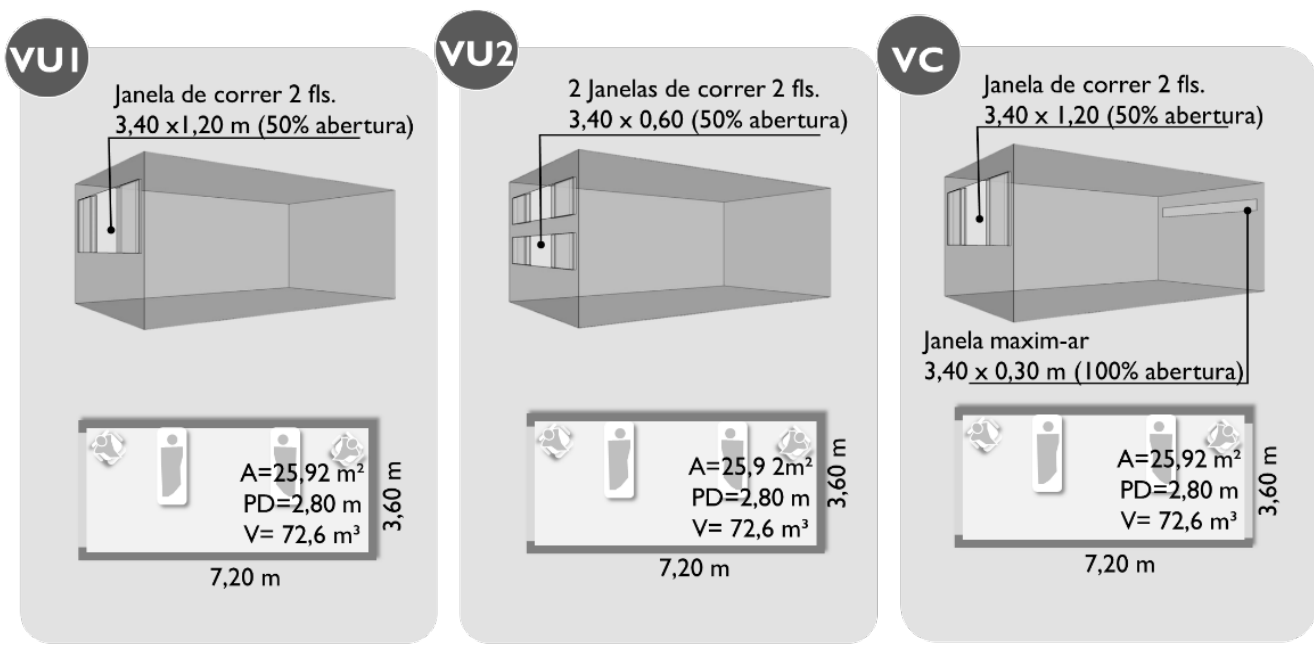

Onde, VUI é ventilação unilateral simples, VU2 é ventilação unilateral dupla, VC é ventilação cruzada, fls é folhas, $\mathrm{A}$ é área útil, $\mathrm{PD}$ é pé direito e $\mathrm{V}$ é volume. 


\section{Demais casos}

Os demais casos mantêm o percentual de abertura e diferenciam-se do caso-base exclusivamente pela disposição das aberturas, sendo elas ventilação unilateral dupla (VU2) e ventilação cruzada (VC). O caso VU2 apresenta duas janelas de correr (2 folhas) de 3,40x0,60 m com duas alturas de peitoril, 0,80 m e 1,40 m, e $50 \%$ de abertura, localizadas na mesma parede. O caso VC foi definido com aberturas em paredes opostas, sendo uma de correr, de 3,40x1,20 m, 1,00 m de peitoril e 50\% de abertura, e outra fixa de 3,40x0,30 m, 1,90 $\mathrm{m}$ de peitoril e $100 \%$ de abertura. Todas as janelas de correr possuem 4 folhas, sendo 2 fixas nas extremidades e 2 móveis no centro.

A Figura 2 ilustra todos os casos dos quartos de internação simulados.

\section{Análise climática}

As simulações CFD representam o comportamento do fluido em regime estacionário. Para isso é necessária a especificação das condições de contorno que se deseja analisar. Esse método de trabalho diferencia-se nos programas de simulação térmica em regime dinâmico que reproduzem as condições climáticas com intervalos horários por meio de arquivos representativos do clima de determinada cidade. Frequentemente utilizado, o arquivo do Ano Climático de Referência (arquivo TRY) contém os dados climáticos horários de um ano típico e sem extremos de temperatura.

A definição das condições de contorno das simulações é caracterizada por dias típicos (SOUTULLO et al., 2014), neste caso definidos segundo a temperatura de maior ocorrência nos histogramas do verão $\left(25^{\circ} \mathrm{C}\right)$ e da primavera $\left(20^{\circ} \mathrm{C}\right)$. Foram selecionados dois dias que tiveram temperatura média igual à de maior ocorrência nos histogramas e com baixa amplitude térmica (aproximadamente $5{ }^{\circ} \mathrm{C}$ no verão e $1{ }^{\circ} \mathrm{C}$ na primavera).

Dessa forma, foram considerados representativos dos períodos de verão e de primavera os dias 21 de janeiro e 5 de outubro respectivamente. As Figuras 3 e 4 indicam a variação da temperatura de bulbo seco (TBS) e a velocidade do ar ao longo dos dias 21 de janeiro e 5 de outubro.

A partir desses histogramas também foram definidas três categorias para a velocidade de entrada do vento na simulação CFD: alta (6 m/s), média (3 m/s) e baixa $(1 \mathrm{~m} / \mathrm{s})$. Embora as velocidades máximas tenham sido de até $8 \mathrm{~m} / \mathrm{s}$ em 21 de janeiro e de até $10 \mathrm{~m} / \mathrm{s}$ em 5 de outubro, estas não representam um valor elevado frequente e, por isso, foi adotado o valor de $6 \mathrm{~m} / \mathrm{s}$ como a categoria de velocidade de entrada do vento alta.

O histograma de frequência de ocorrência (Figura 5) apresenta a predominância dos ventos por direção. Os ventos mais frequentes nos dias 21 de janeiro e 5 de outubro são os ventos norte (69\%) e nordeste (38\%) respectivamente. Essas direções também predominam ao longo do verão, da primavera e do outono.

\section{Definição das condições de contorno}

Com base nas análises climáticas, foram estabelecidas as condições de contorno para as simulações apresentadas na Tabela 1.

Figura 3 - TBS e velocidade do ar no dia 21 de janeiro

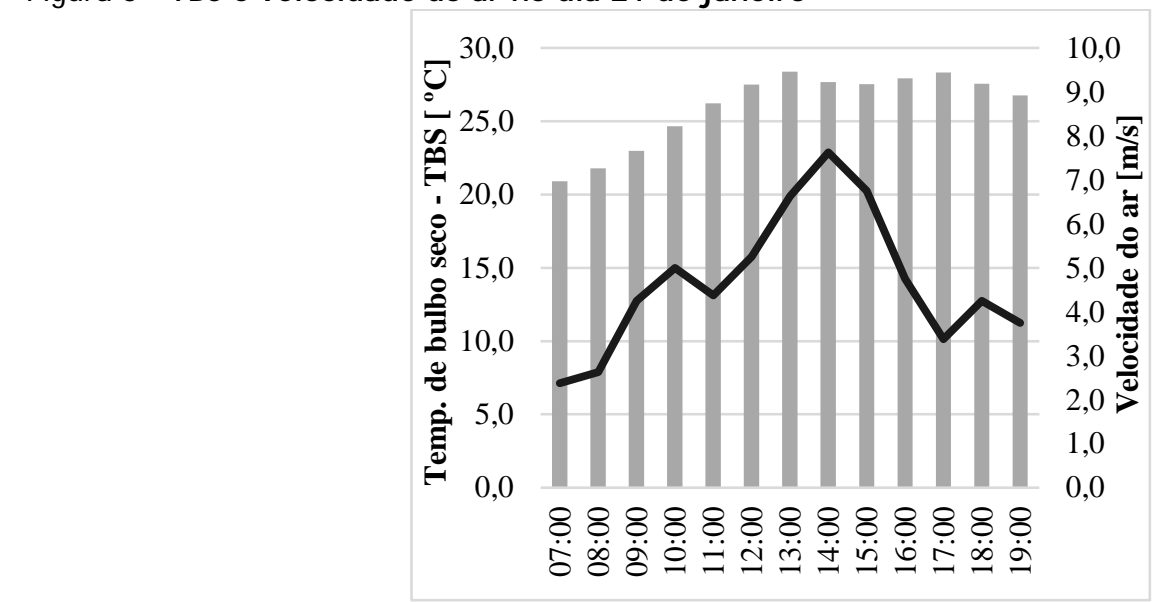

Nota: Legenda:

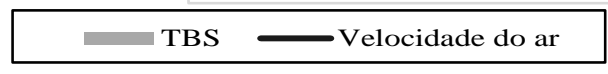


Figura 4 - TBS e velocidade do ar no dia 5 de outubro

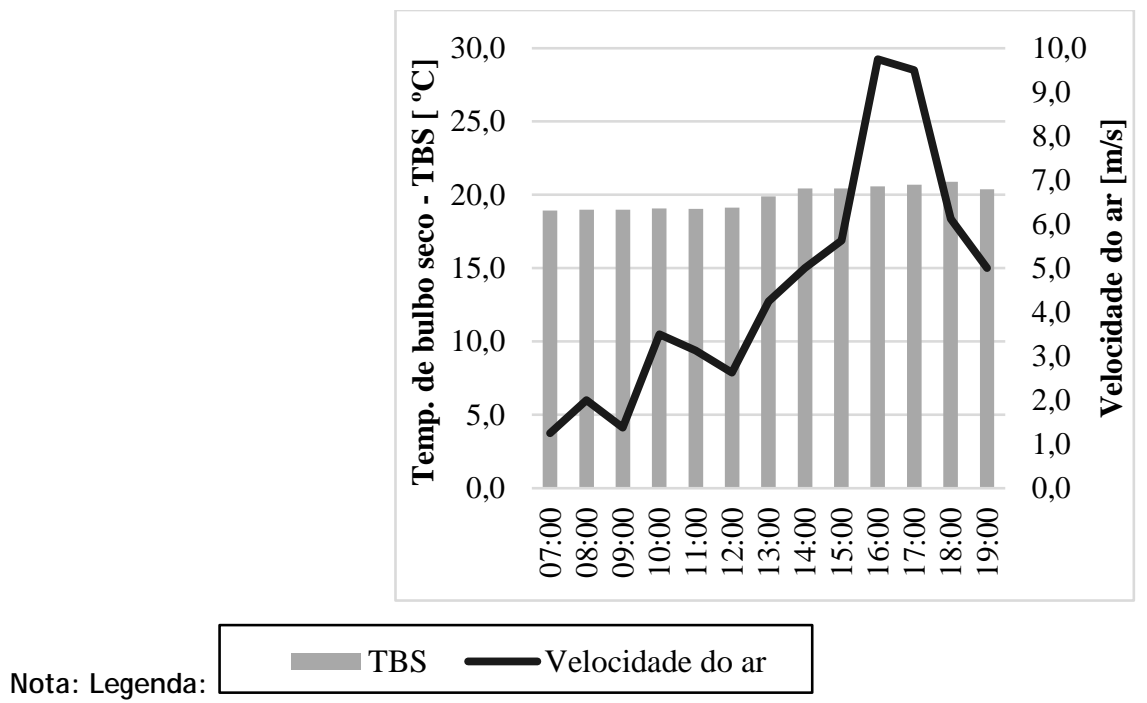

Figura 5 - Histograma de frequência de ocorrência dos ventos nos dias típicos dos períodos de verão e primavera

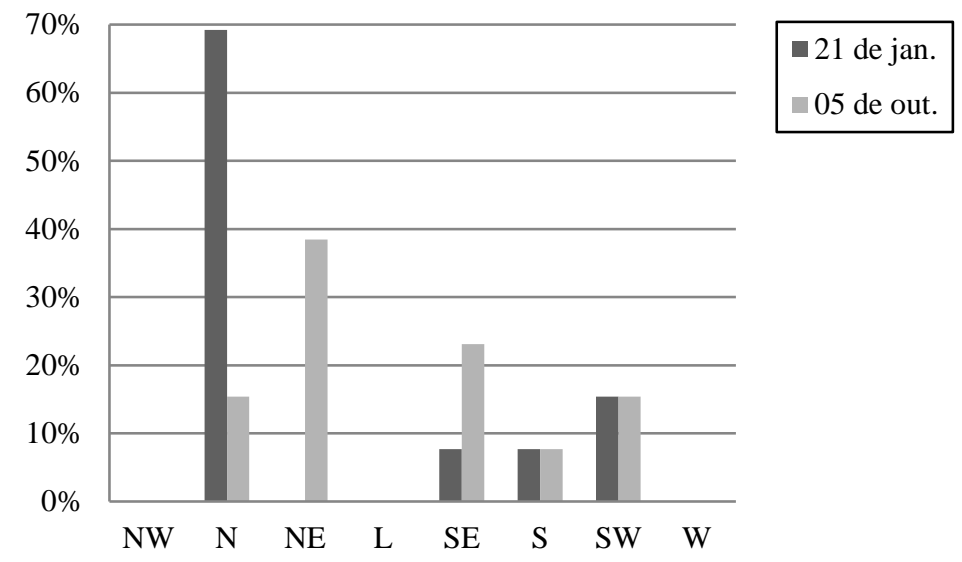

Tabela 1 - Condições de contorno

\begin{tabular}{l|c|l|l|l|l|l}
\hline Período & Temperatura do ar externo & \multicolumn{2}{|c|}{ Direção do vento } & \multicolumn{2}{|c}{ Velocidades do ar } \\
\hline Verão & $25,0^{\circ} \mathrm{C}$ & \multirow{2}{*}{ Norte } & Nordeste & $1 \mathrm{~m} / \mathrm{s}$ & $3 \mathrm{~m} / \mathrm{s}$ & $6 \mathrm{~m} / \mathrm{s}$ \\
\hline Primavera & $20,0^{\circ} \mathrm{C}$ & & &
\end{tabular}

\section{Determinação das cargas térmicas}

A carga térmica do quarto é composta dos usuários, da iluminação artificial e do ganho de calor pela parede externa devido à radiação solar. Esses objetos são considerados uma fonte de energia por meio de um fluxo fixo de calor, que pode ser especificado como um fluxo total para o objeto ou como um fluxo por unidade de área.

Os usuários do quarto consistem em dois pacientes e dois acompanhantes, totalizando quatro usuários, com atividade metabólica de $60 \mathrm{~W} / \mathrm{m}^{2}$ cada um (AMERICAN..., 2013). A carga térmica de iluminação artificial se baseia nos Requisitos Técnicos da Qualidade para o Nível de Eficiência Energética de Edifícios Comerciais, de Serviços e Públicos (INSTITUTO..., 2010). Para que um hospital seja classificado como de nível A, a densidade de potência de iluminação limite é de $13,0 \mathrm{~W} / \mathrm{m}^{2}$. Considerando que a área do quarto de internação é de 25,92 m², a carga térmica pela iluminação artificial resulta em $320 \mathrm{~W}$, distribuídos por 5 luminárias com 2 lâmpadas de $32 \mathrm{~W}$ cada. 
Para a modelagem da ventilação natural foi considerado que o quarto de internação se localiza em um pavimento médio (nível de +6,40 m em relação à rua) e voltado para a orientação norte, com o intuito de buscar o melhor aproveitamento dos ventos predominantes em Florianópolis. Assim, é considerado na modelagem que apenas a parede norte está em contato com o meio externo. As demais superfícies adjacentes à parede externa são consideradas adiabáticas. Para contemplar o efeito da radiação solar, o programa CFD utilizado (Phoenics) requer informações sobre o fluxo fixo de calor pelas paredes que não são consideradas adiabáticas. Por não ser o objetivo principal do estudo, o fluxo fixo de calor é calculado de forma simplificada, de acordo com a Equação 1 para a parede externa e com a Equação 2 para as janelas. Os cálculos apresentam como referência a norma de desempenho térmico em edificação NBR 15220-2 (ABNT, 2005).

Os dados para o cálculo do fluxo fixo de calor na parede externa e nas janelas são apresentados na Tabela 2. A janela recebe vidro incolor simples de $3 \mathrm{~mm}$, e a parede possui $14 \mathrm{~cm}$ de espessura, construída em alvenaria de tijolos de seis furos com reboco interno e externo de $15 \mathrm{~mm}$ em argamassa e pintura branca.

$\mathrm{Q}=\mathrm{U} \cdot((\alpha \cdot \mathrm{I} \cdot \mathrm{Rse})+\mathrm{Text}-\mathrm{T}$ int $)$

Eq. 1

$\mathrm{Q}=\mathrm{U} \cdot($ Text - Tint $)+\mathrm{Fs} \bullet \mathrm{I}$,

Onde:

Q: fluxo fixo de calor;

$\mathrm{U}$ : transmitância térmica $\left(\mathrm{W} /\left(\mathrm{m}^{2} . \mathrm{K}\right)\right)$;

$\alpha$ : absortividade da superfície (adimensional);

I: radiação solar incidente $\left(\mathrm{W} / \mathrm{m}^{2}\right)$;

Rse: resistência superficial externa;

Fs: fator solar;

Text: temperatura externa (K); e

Tint: temperatura interna (K).

Os dados de absortividade da superfície e o fator solar foram extraídos do Projeteee (2019). A radiação solar total incidente (I) foi obtida pelo programa Radiasol, desenvolvido em 2001 pelo Laboratório de Energia Solar da Universidade Federal do Rio Grande do Sul, que adota o banco de dados do projeto Swera (NATIONAL..., 2011). Foi utilizado o valor da radiação solar média na fachada norte durante o horário mais crítico. Nos períodos de verão e de primavera, os valores se referem à radiação solar média para os meses de janeiro e de outubro às $12 \mathrm{~h}$ respectivamente.

A diferença de temperatura entre o ambiente externo e o interno foi estimada por meio de tabela desenvolvida por González (2013), denominada Cálculo de la Temperatura Media Interior em Región Caliente. Esse cálculo é simplificado e utiliza os seguintes dados: temperatura do ar externo, oscilação da temperatura do ar externo, dimensões do ambiente, área de janela, propriedades térmicas da envoltória, radiação solar média diária do mês analisado, cargas térmicas (iluminação e ocupação) e trocas de ar por hora mínima estimada.

\section{Simulação CFD}

O programa utilizado é o Phoenics, desenvolvido pela empresa britânica Cham. Esse programa dispõe do módulo Flair, que possui uma interface mais amigável para a visualização, avaliação e refinamento do fluxo de ar na malha urbana ou no interior das edificações. O maior avanço do módulo Flair é a facilidade na representação e na construção da geometria do modelo de estudo em três dimensões.

Tabela 2 - Cálculo do fluxo fixo de calor

\begin{tabular}{c|c|c|c|c|c|c|c}
\hline $\begin{array}{c}\text { Uparede } \\
{\left[\mathbf{W} /\left(\mathbf{m}^{2} \cdot \mathbf{K}\right)\right]}\end{array}$ & $\begin{array}{c}\text { Uvidro } \\
{\left[\mathbf{W} /\left(\mathbf{m}^{2} \mathbf{. K}\right)\right]}\end{array}$ & $\alpha$ & Fs & Rse & $\Delta \mathbf{T}$ & Iverão $\left[\mathbf{W} / \mathbf{m}^{2}\right]$ & Iprimavera $\left[\mathbf{W} / \mathbf{m}^{2}\right]$ \\
\hline 2,48 & 5,70 & 0,20 & 0,88 & 0,04 & 0,80 & 291 & 377 \\
\hline
\end{tabular}

Nota: Legenda:

$Q$ parede no verão $=7,76 \mathrm{~W} / \mathrm{m}^{2}$;

$\mathrm{Q}$ vidro no verão $=260,64 \mathrm{~W} / \mathrm{m}^{2}$;

Q parede na primavera $=9,46 \mathrm{~W} / \mathrm{m}^{2} ; \mathrm{e}$

$Q$ vidro na primavera $=336,32 \mathrm{~W} / \mathrm{m}^{2}$. 


\section{Construção da geometria}

Por tratar-se de uma geometria simples, a envoltória, o mobiliário e os usuários do quarto de internação foram modelados dentro do Phoenics (Figura 6). O programa disponibiliza uma biblioteca própria de materiais para serem aplicados aos elementos modelados. As propriedades térmicas desses materiais podem ser editadas e permitem maior aproximação com a realidade dos objetos de estudo.

Para que o modelo CFD execute simulações nas quais o domínio é o próprio ambiente interno, é necessária a indicação de aberturas de entrada e de saída de ar. Conforme ilustra a Figura 6, as janelas foram modeladas como os objetos Inlet, responsável pela entrada de ar, e Opening, que admite tanto o ingresso quanto a saída de ar, dependendo das pressões geradas nos ambientes externo e interno (SPALDING, 1994). A configuração do objeto Inlet na parte inferior da abertura e do objeto Opening na parte superior considera o efeito conjunto da ação do vento e da diferença de temperatura. Conforme observado na revisão bibliográfica, estudos apresentam casos de ventilação unilateral em que o fluxo de ar pode entrar pela porção inferior da abertura e sair pela porção superior, sob a ação do efeito conjunto (ALLOCCA; CHEN; GLICKSMAN, 2003; STABAT; CACIOLO; MARCHIO, 2012). Nessa situação, o fluxo de ar é invertido na altura do nível de pressão neutra (NPL). Segundo Stabat, Caciolo e Marchio (2012), a altura do NPL depende da distribuição e das características das aberturas. Para simplificar a modelagem, o NPL foi localizado no meio da janela, dividindo a abertura em duas (Inlet e Opening). Ressalta-se que no quarto com ventilação cruzada a abertura oposta funciona como um campo aberto, sem considerar a interferência de um corredor de circulação.

O objeto Inlet permite atribuir uma temperatura inicial ao fluxo de vento, neste caso igual à temperatura exterior dos contextos, e uma velocidade do vento em um dos vários eixos principais ( $x, y$ e $z$ ). Nos eixos $y$ e $x$ foram definidas as velocidades do vento, de acordo com cada caso $(1,0 \mathrm{~m} / \mathrm{s} ; 3,0 \mathrm{~m} / \mathrm{s}$ ou $6,0 \mathrm{~m} / \mathrm{s})$, como componente negativo para indicar sua proveniência, do norte ou do nordeste.

A envoltória, o mobiliário e as luminárias dos três quartos de internação foram definidos como objetos denominados Blockages. Cada Blockage constitui-se em um volume sólido com materiais a definir. As paredes, o piso e a cobertura adotaram o material solid with smooth-wall friction. No caso das paredes externas consideradas como fontes de energia pela troca de calor com o ambiente externo, foram inseridos os valores do fluxo fixo de calor e a transmitância térmica.

O material dos leitos dos pacientes e o das poltronas dos acompanhantes foram definidos como material similar to steel timber flooring e woodblock respectivamente. As luminárias foram especificadas em aluminium com $64 \mathrm{~W}$ de potência cada, considerando o cálculo anterior de carga térmica para iluminação.

Figura 6 - Geometria dos quartos de internação hospitalar

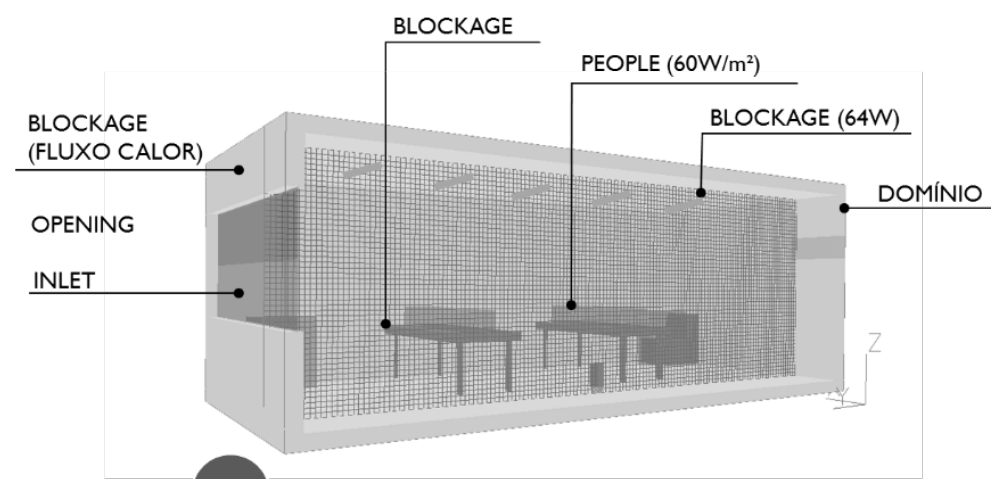

VU1 VENTILAÇÃO UNILATERAL SIMPLES

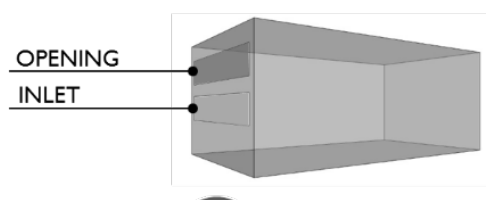

VU2

VENTILAÇÃO

UNILATERAL DUPLA

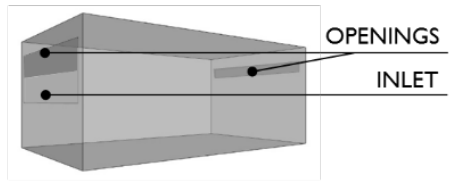

VC VENTILAÇÃO CRUZADA 
Além disso, os usuários foram inseridos como objeto People, o qual não impede o fluxo do ar (SPALDING, 1994) e funciona como uma fonte de calor de $60 \mathrm{~W} / \mathrm{m}^{2}$, representando uma pessoa sentada e relaxada (AMERICAN..., 2013). Considerando que área da superfície do corpo humano é de aproximadamente $1,8 \mathrm{~m}^{2}$, a carga térmica resulta em $108 \mathrm{~W}$.

\section{Domínio e malha de avaliação}

O trabalho desenvolvido por Baskaran e Kashef (1996) sugere que o tamanho do domínio pode ser um múltiplo da altura do edifício. Spalding (1994) sugere que, no caso de análises na escala do ambiente interno por meio do programa Phoenics, o domínio seja considerado como a própria geometria do ambiente e que as aberturas sejam modeladas como objetos de entrada e saída do ar. Seguindo a sugestão, o domínio do modelo apresentado na Figura 7 segue as dimensões dos quartos de internação, apresentando um volume de $72,58 \mathrm{~m}^{3}$ $(7,20 \times 3,60 \times 2,80 \mathrm{~m})$.

As condições de contorno iniciais são especificadas nas propriedades do domínio. Diversos estudos discutem a adequação dos diferentes modelos de turbulência a partir das características dos modelos de simulação. Nesta pesquisa, o modelo de turbulência adotado foi o LVEL por ser o modelo mais adequado quando a simulação envolve os fluxos de ar e de transferência de calor simultaneamente (SPALDING, 1994).

A malha de avaliação é responsável por capturar os diversos elementos construtivos que interferem no fluxo de ar. Existem três tipos de malhas espaciais: cartesiano, cilíndrico polar e BFC (body-fitted). A malha adotada é a do tipo cartesiano, por ser amplamente utilizada em estudos de desempenho da ventilação natural em edificações. Essa malha é composta de células que remetem a tijolos retangulares de seis lados, sendo todas as linhas da malha retas. A Figura 8 apresenta um detalhe de um plano de faces da malha de avaliação do modelo.

Tendo como base o domínio e a geometria criada, o programa gera uma malha padrão. Neste caso houve a necessidade de refinamento da malha para possibilitar a identificação apurada de todos os objetos, resultando em uma malha de distribuição homogênea, com células de 0,1x0,1x0,1 m. Assim, tem-se um total de 72 células no eixo $x$, 36 células no eixo $y$, e 28 células no eixo $z$.

\section{Número de iterações}

A ponderação entre os erros residuais e o tempo de simulação determinou o número de iterações. O programa exibe gráficos de convergência, os quais apontam, ao longo do processo de simulação, os erros residuais e a variação dos valores das variáveis de saída (Figura 9).

Figura 7 - Domínio do modelo

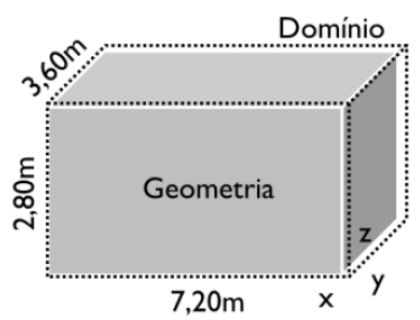

Figura 8 - Detalhe da malha de avaliação

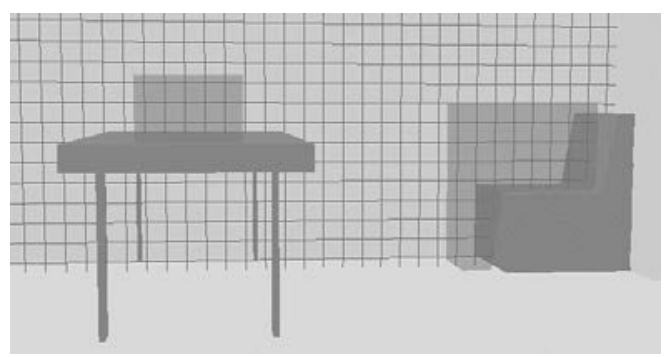


Figura 9 - Gráficos de convergência
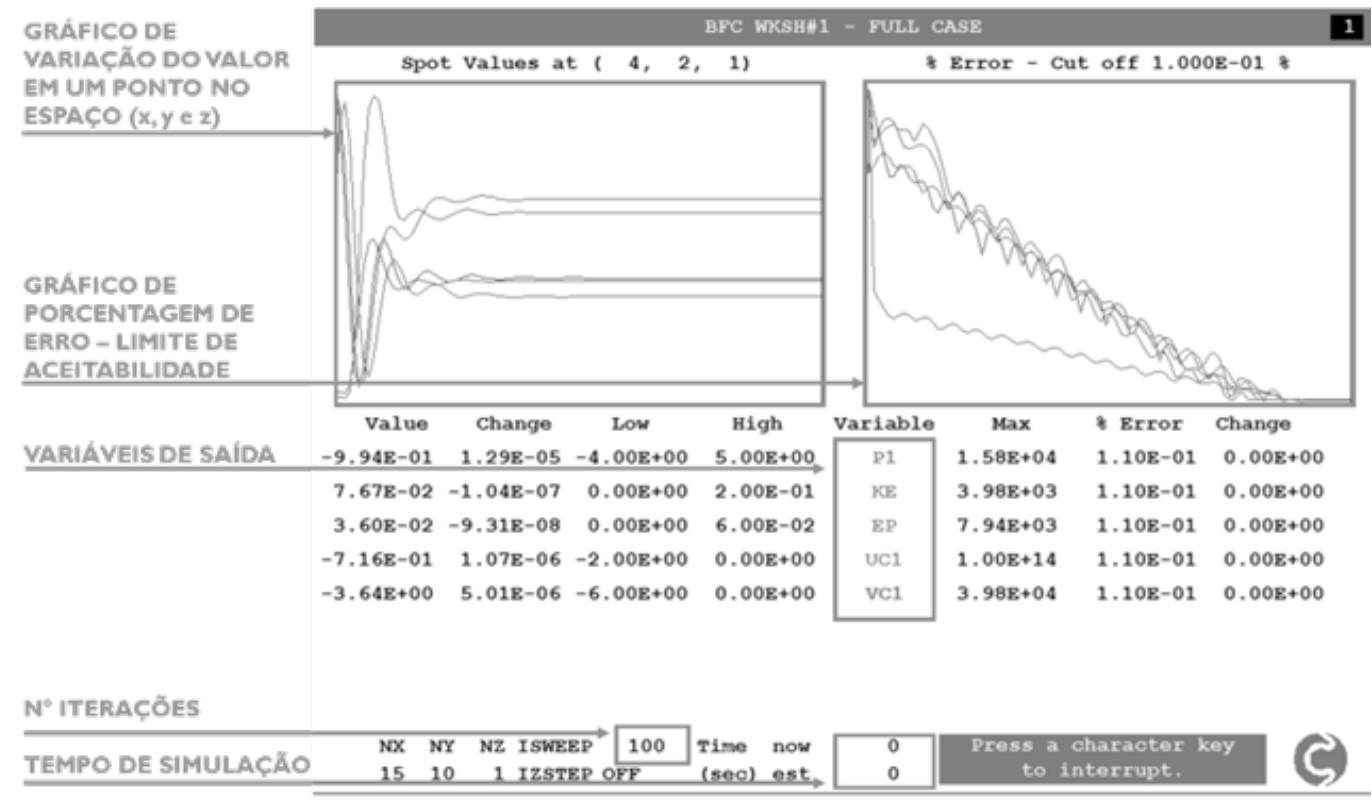

De acordo com Spalding (1994), o número mínimo iterações ideal é aquele no qual os valores de todas as variáveis climáticas (temperatura do ar, velocidade do ar, entre outras) variam em um nível considerado aceitável. Na prática, isso significa que, ao iniciar a simulação, as variáveis climáticas sofrem grandes oscilações, que devem decair ao longo do processo. Quando o valor das variáveis estabilizarem (Figura 9 gráfico de variação de valor em um ponto) e os erros residuais atingirem 0,1\% (Figura 9 - gráfico de porcentagem de erro), a simulação terá convergido.

Após simulações prévias, observou-se a convergência dos resultados para 5.000 iterações. Foram realizadas 36 simulações em computadores com processador Intel Core i5-2400, com um tempo médio de 3 h por simulação.

\section{Critério de avaliação do conforto térmico}

Embora haja estudos de avaliação do conforto térmico em hospitais (LOMAS; JI, 2009; ADAMU; PRICE; COOK, 2012; SALONEN et al., 2013; RUPP; VÁZQUEZ; LAMBERTS, 2015), não há uma recomendação específica de limites de conforto térmico para pessoas enfermas. Assim, nesta pesquisa são utilizados os limites de faixa de conforto para adultos saudáveis.

Um estudo investigou a preferência dos usuários em relação à preferência e à aceitabilidade da movimentação do ar na cidade de Maceió, AL. Os resultados indicam que é significativa a percentagem dos usuários que preferem maiores velocidades do ar do que os limites estabelecidos pelas normas internacionais (CANDIDO et al., 2010). Observa-se que futuras normas brasileiras devem visar limites de velocidade que correspondam à expectativa dos usuários em climas quentes e úmidos.

A abordagem adaptativa considera que as condições climáticas nas quais o indivíduo esteve exposto nos últimos dias influenciam seu comportamento de adaptação ao ambiente térmico (DE DEAR; BRAGER, 2002). Dessa forma, o conforto térmico depende da temperatura operativa e da temperatura média predominante do ar externo baseada, no mínimo, nos 7 últimos dias antes do dia da avaliação (AMERICAN..., 2013).

Considerando os dias típicos adotados para o verão e a primavera, a temperatura média predominante do ar externo foi calculada pela média aritmética das temperaturas médias para os 7 dias anteriores $\left(\mathrm{T}_{o d-1}, \mathrm{~T}_{o d-2, \ldots}\right)$ aos dias 21 de janeiro e 5 de outubro. O cálculo feito com base na Equação 3 (AMERICAN..., 2013) resulta em uma temperatura média predominante de $23,1{ }^{\circ} \mathrm{C}$ para o verão e de $16,8^{\circ} \mathrm{C}$ para a primavera.

Tmpa $=0,34 \mathrm{~T}_{\text {od- }-1}+0,23 \mathrm{~T}_{\text {od-2 }}+0,16 \mathrm{~T}_{\text {od- }-3}+0,11 \mathrm{~T}_{\text {od- }-4}+0,08 \mathrm{~T}_{\text {od- }-5}+0,05 \mathrm{~T}_{\text {od- }-6}+0,03 \mathrm{~T}_{\text {od- }-7}$

Onde:

$\mathrm{T}_{\text {mpa }}(\mathrm{ext})$ : temperatura média predominante do ar externo $\left({ }^{\circ} \mathrm{C}\right)$; 
$\mathrm{T}_{\text {od-1 }}$ : temperatura média do dia anterior $\left({ }^{\circ} \mathrm{C}\right)$;

$\mathrm{T}_{\text {od-2}}$ : temperatura média 1 dia antes do anterior;

$\mathrm{T}_{\text {od-3: }}$ temperatura média 2 dias antes do anterior; e

assim por diante.

Com base nos valores calculados para as temperaturas médias predominantes do ar externo, modificou-se o gráfico de faixas de temperaturas operativas aceitáveis para espaços naturalmente ventilados (Figura 10) de forma a considerar a temperatura média predominante constante, somente variando as temperaturas operativas que foram obtidas pelas simulações.

Uma vez que ambientes com temperatura operativa superior a $25,0^{\circ} \mathrm{C}$ podem ter os limites da zona de conforto ampliados quando sujeitos à velocidade do ar acima de $0,3 \mathrm{~m} / \mathrm{s}$, foram consideradas as correções do limite superior da zona de conforto para velocidades do ar de $0,3 \mathrm{~m} / \mathrm{s}$ a $0,6 \mathrm{~m} / \mathrm{s}$; de $0,6 \mathrm{~m} / \mathrm{s}$ a $0,9 \mathrm{~m} / \mathrm{s}$; e de $0,9 \mathrm{~m} / \mathrm{s}$ a $1,2 \mathrm{~m} / \mathrm{s}$. A ASHRAE Standard 55 (AMERICAN..., 2013) prevê um aumento no limite superior da temperatura operativa de conforto de $1,2{ }^{\circ} \mathrm{C}, 1,8{ }^{\circ} \mathrm{C}$ e $2,2^{\circ} \mathrm{C}$ para essas três categorias de velocidade de entrada do vento respectivamente.

A abordagem adaptativa utiliza a temperatura operativa para se aproximar da sensação térmica pelo fato de esta ser influenciada pela temperatura do ar, pela velocidade do ar e pela temperatura radiante média. O cálculo dessa variável pelo software Phoenics é baseado na Equação 4.

To $=\frac{\operatorname{Trad}+\operatorname{Ta} \times(10 \times \mathrm{V})^{0,5}}{1+(10 \times \mathrm{V})^{0,5}}$,

Onde:

TO: temperatura operativa $\left({ }^{\circ} \mathrm{C}\right)$;

Trad: temperatura radiante média $\left({ }^{\circ} \mathrm{C}\right)$;

Ta: temperatura do ar interno $\left({ }^{\circ} \mathrm{C}\right)$; e

$\mathrm{V}$ : velocidade média do ar interno $(\mathrm{m} / \mathrm{s})$.

Figura 10 - Faixas de temperaturas operativas aceitáveis para espaços naturalmente ventilados

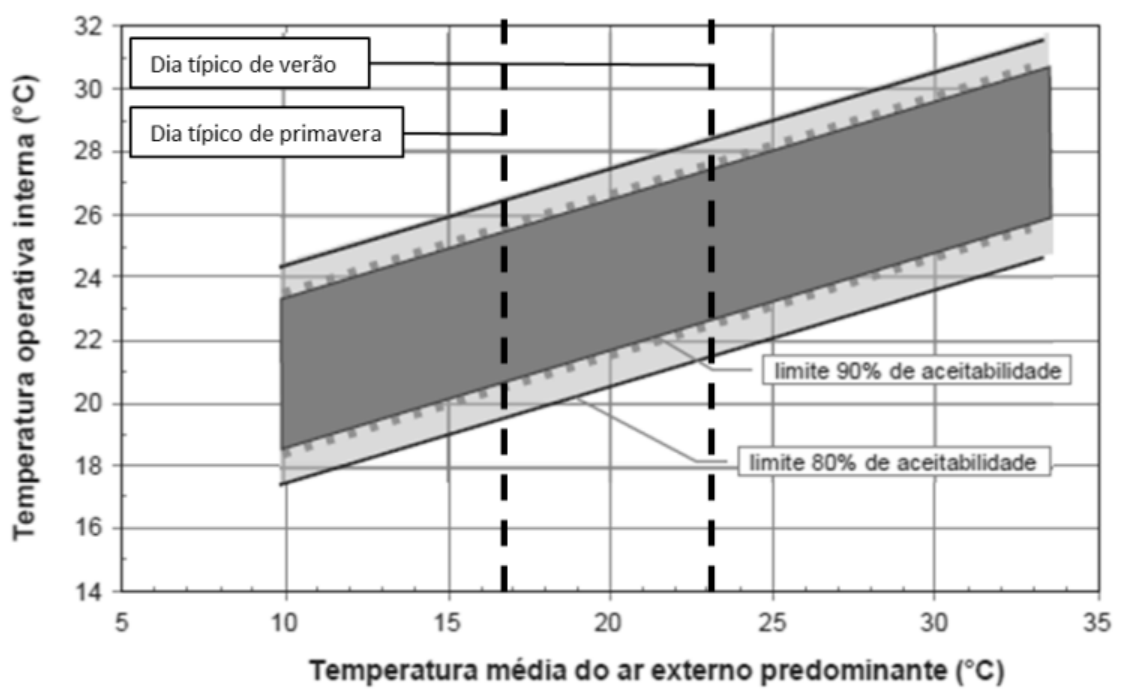

Fonte: adaptada de Hoyt et al. (2018). 


\section{Resultados e discussões}

Os resultados obtidos com as simulações permitiram analisar a influência de cada forma de ventilação e da direção do vento sobre a velocidade do ar interno. A Figura 11 indica as velocidades médias do ar interno para os diferentes quartos expostos aos ventos externos norte e nordeste de até $6 \mathrm{~m} / \mathrm{s}$. O gráfico aponta que a variação da velocidade média do ar no interior do quarto de internação foi de 0,58 m/s a 1,02 m/s, valores significativos para o conforto térmico. Observa-se que o caso VU1 apresenta pouca sensibilidade à direção do vento. Isso porque a entrada e a saída de ar se encontram na mesma abertura, o que dificulta o livre escoamento. Por outro lado, o caso VC facilita o escoamento do ar e, por isso, apresenta as maiores velocidades de ar interno. Esse aumento chega a 25\% se comparado com o caso VU2 e a $70 \%$ se comparado com o caso VU1.

As maiores velocidades médias do ar interno ocorrem com a adoção da ventilação cruzada (VC), de 1,02 m/s e $0,73 \mathrm{~m} / \mathrm{s}$ para os ventos norte e nordeste respectivamente. Em seguida aparece a ventilação unilateral dupla (VU2), resultando em velocidade média de $0,80 \mathrm{~m} / \mathrm{s}$ para o vento norte e de $0,73 \mathrm{~m} / \mathrm{s}$ para o vento nordeste. $\mathrm{O}$ quarto em que ventilação unilateral ocorre através de apenas uma janela (VU1) apresenta as menores velocidades do ar, de $0,59 \mathrm{~m} / \mathrm{s}$ e $0,58 \mathrm{~m} / \mathrm{s}$ para os ventos norte e nordeste respectivamente. Esses resultados corroboram os encontrados por Adamu, Price e Cook (2012), que apontam significante variação na velocidade do ar para as seguintes configurações: abertura unilateral simples, abertura unilateral dupla, abertura unilateral com torre de ventilação e abertura unilateral com saída pelo forro.

Apesar das diferenças no comportamento da ventilação discutido anteriormente, nota-se que os casos VC e VU2 apresentam o mesmo valor de velocidade média do ar interno quando expostos ao vento nordeste. Essa situação confirma resultados de estudo anteriores que indicam que nem sempre o desempenho da ventilação cruzada é superior ao da ventilação unilateral. Chenari, Dias Carrilho e Gameiro da Silva (2016) apontam um desempenho similar entre ambas as configurações no caso de ventos desfavoráveis em termos de direção e velocidade. Portanto, pelo fato de o vento nordeste incidir com inclinação de $45^{\circ}$ em relação à fachada do quarto, as diferenças encontradas entre os casos foram menos expressivas do que para o vento norte, que incide perpendicularmente.

Com o vento favorável de direção norte, o caso VC apresenta maior elevação na velocidade do ar quando comparado com o vento nordeste, chegando a um aumento de 28\%. O mesmo não ocorre com os casos VU1 e VU2, em que a diferença entre o desempenho do vento norte e nordeste é insignificante. Para o caso VU1 esse aumento é de 1\%, e para o caso VU2 esse aumento é de 10\%. Os resultados confirmam as constatações do estudo feito por Ayata e Yildiz (2006) de que, além da configuração das aberturas, a orientação do edifício de acordo com o vento predominante pode melhorar substancialmente o desempenho da ventilação natural.

Figura 11 - Velocidade média do ar interno para os casos VU1, VU2 e VC com ventos norte e nordeste de até $6 \mathrm{~m} / \mathrm{s}$

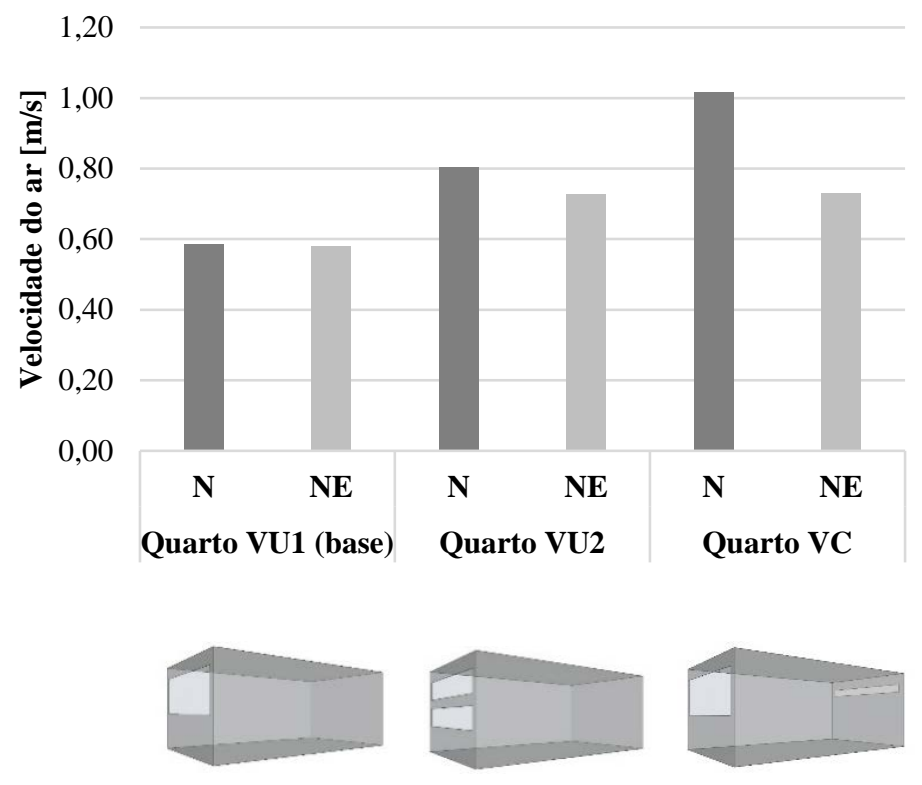




\section{Distribuição da velocidade do ar interno}

Apesar de o ambiente estar exposto a um vento externo de mesma direção e velocidade, os usuários estão sujeitos a distintas condições de ventilação em função da distribuição do fluxo de ar no ambiente interno. Essa análise qualitativa adotou a simulação com vento médio $(3 \mathrm{~m} / \mathrm{s})$ para mostrar as diferenças na distribuição do fluxo de ar no ambiente interno. A Figura 12 apresenta a velocidade do ar sobre cada usuário para o caso VU1.

Com o vento norte, a sequência do percurso do ar é $\mathrm{A} 1 \rightarrow \mathrm{A} 2 \rightarrow \mathrm{P} 2 \rightarrow \mathrm{P} 1$. Dessa forma, os resultados demonstram que o percurso do ar não segue a sequência esperada, que iria do ocupante mais próximo à janela para o mais afastado. Por estar mais próximo à janela, apenas o acompanhante 1 está sujeito ao fluxo de ar de entrada. Logo em seguida, parte desse fluxo de ar sai pela porção superior da janela, e outra parte continua seu percurso pelo teto até encontrar o acompanhante 2, na parede dos fundos.

Com relação à distribuição dos ventos, a variação da velocidade do ar interno vai de $0,30 \mathrm{~m} / \mathrm{s}$ sobre o paciente 1 (P1) a 0,45 m/s sobre o acompanhante 1 (A1). Os resultados confirmam a relação direta entre velocidade do ar interno e sequência do percurso do fluxo de ar. Essa relação também foi observada por Prajongsan e Sharples (2012) em suas simulações CFD para analisar a eficiência do uso de torres de ventilação na parede oposta à entrada de ar em apartamentos em Bangkok. Os pesquisadores observaram que, à medida que o ar percorre o ambiente, sua velocidade reduz e volta a aumentar antes de encontrar uma saída. Essa queda na velocidade do ar ocorre em função das barreiras arquitetônicas (paredes, mobiliários) encontradas pelo fluxo de ar.

O percurso do fluxo de ar com o vento incidindo na direção nordeste é alterado, e, consequentemente, a distribuição da velocidade do ar interno também se modifica, seguindo a sequência $\mathrm{P} 2 \rightarrow \mathrm{A} 2 \rightarrow \mathrm{P} 1 \rightarrow \mathrm{A} 1$. Apesar de P2 estar mais afastado da janela de entrada do ar, é ele o primeiro a ser atingido pelo fluxo de ar em função do ângulo de incidência de $45^{\circ}$ do vento nordeste. Novamente, a distribuição da velocidade do ar interno apresenta relação direta com a sequência do percurso do ar, variando de 0,35 m/s (A1) a 0,60 m/s (P2).

Conforme demonstram as Figuras 12 e 13, o escoamento do ar é semelhante em ambos os casos com ventilação unilateral. Independentemente de a configuração da abertura ser simples (VU1) ou dupla (VU2), a sequência do fluxo do ar é a mesma.

Apesar das semelhanças, observam-se no caso VU2 valores de velocidades do ar interno levemente superiores aos do caso VU1. Enquanto o caso VU1 apresenta velocidade média de 0,40 m/s, o caso VU2 resulta em uma média de $0,47 \mathrm{~m} / \mathrm{s}$ sobre os usuários.

Figura 12 - Velocidade do ar sobre cada usuário para o caso VU1
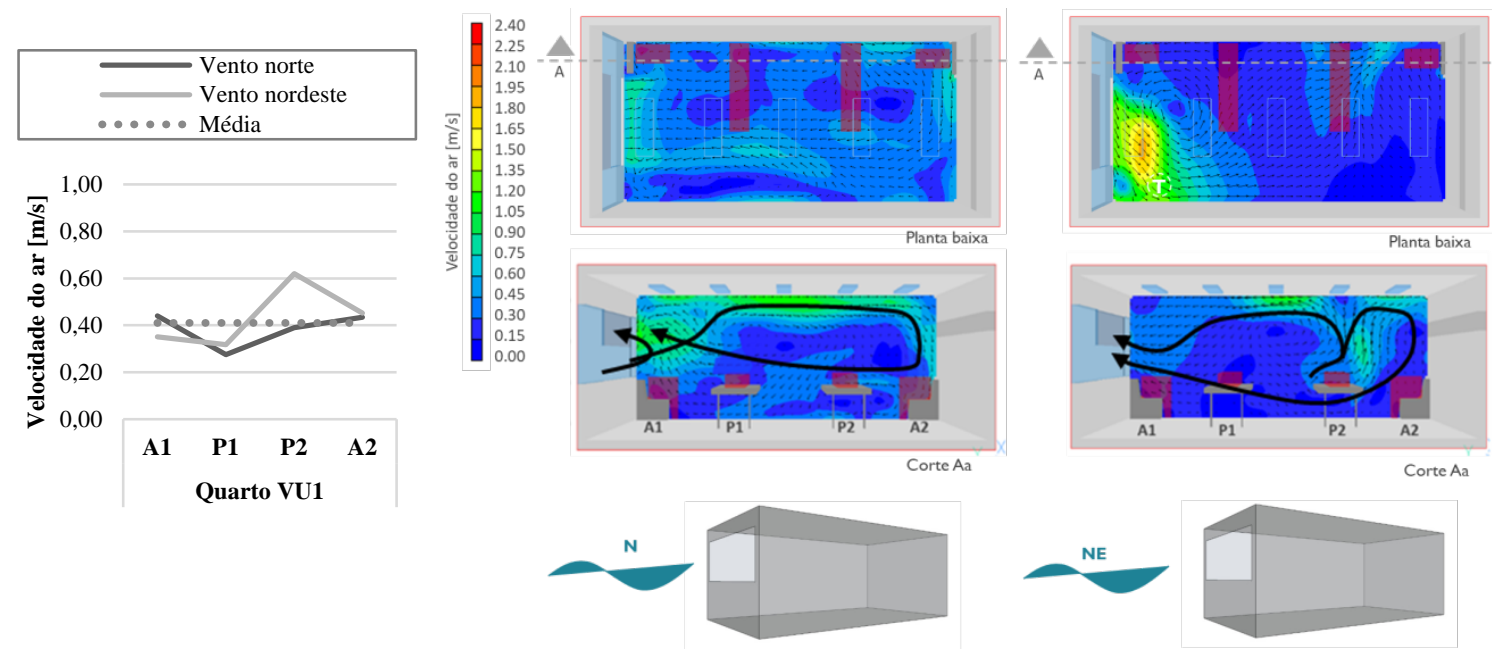

NE

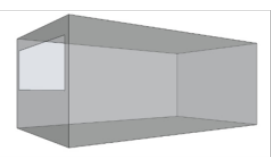


Figura 13 - Velocidade do ar sobre cada usuário para o caso VU2
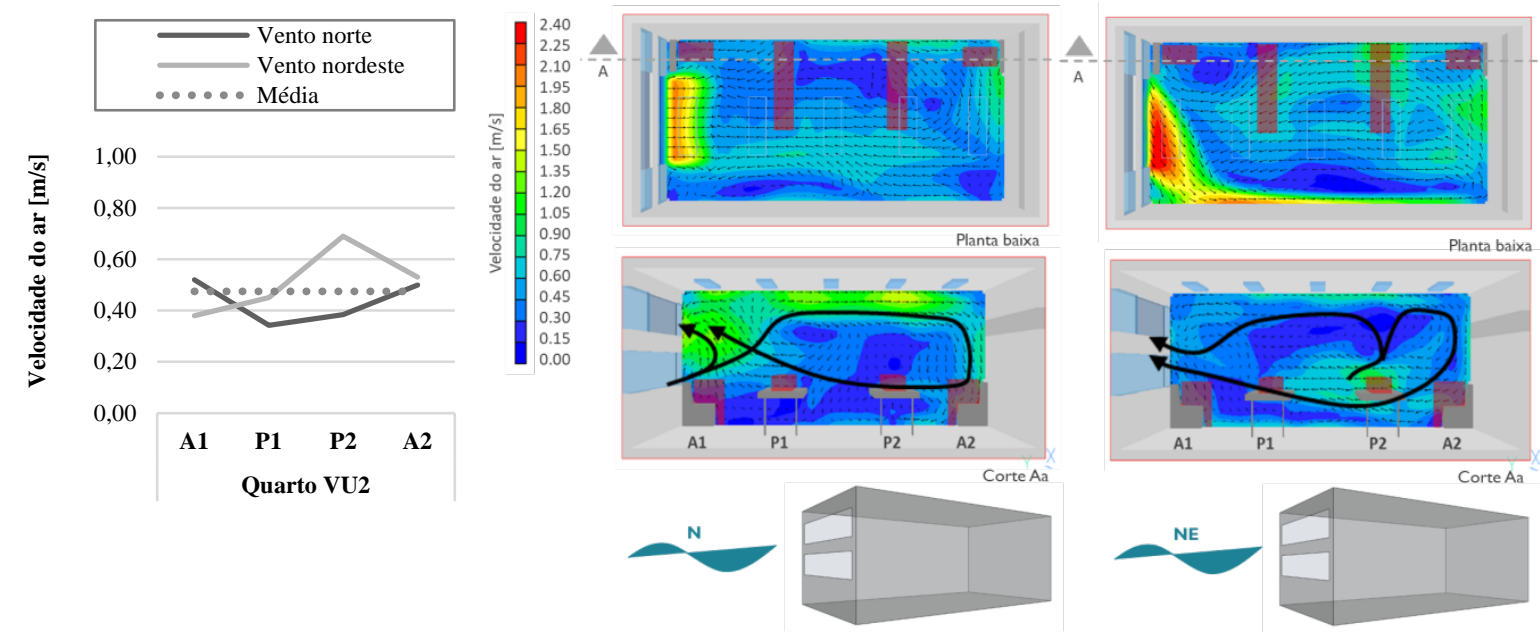

O comportamento do fluxo de ar no caso VC se distingue do dos casos VU1 e VU2. Ao contrário dos casos anteriores, a movimentação do ar é semelhante para os ventos norte e nordeste. Para ambas as direções do vento, a sequência do percurso do ar é $\mathrm{P} 2 \rightarrow \mathrm{P} 1 / \mathrm{A} 1 \rightarrow \mathrm{A} 2$. Conforme ilustra a Figura 14, logo que entra no caso VC, o fluxo de ar segue seu percurso pelo teto, desviando da área ocupada pelos usuários. A seguir, parte desse fluxo sai pela abertura oposta à entrada do ar e parte retorna para sair pela janela principal. Ao retornar, o fluxo de ar se torna descendente e atinge diretamente o paciente 2, o que resulta na maior velocidade do ar entre os usuários.

Com relação à distribuição dos ventos, a variação da velocidade do ar interno vai de $0,30 \mathrm{~m} / \mathrm{s}$ sobre o A2 a 0,8 $\mathrm{m} / \mathrm{s}$ sobre o P2. A baixa influência da ventilação natural sobre o A2 ocorre devido à altura elevada da abertura de saída, que distancia o fluxo de ar da área em que se encontra esse acompanhante. Assim como nos estudos de Prajongsan e Sharples (2012), o fluxo de ar de retorno ganha velocidade antes de sair pela janela principal, aumentando a velocidade do ar sobre o A1 em comparação ao P1.

As curvas no gráfico da Figura 14 demonstram um comportamento semelhante da velocidade do ar para os ventos norte e nordeste, porém com diferença nas velocidades alcançadas. O mesmo não ocorre nos quartos com ventilação unilateral (Figuras 12 e 13), em que se observam claras diferenças quando expostos aos ventos norte e nordeste.

\section{Conforto térmico no período de verão}

O conforto adaptativo para os usuários dos diferentes quartos de internação em um dia típico de verão é apresentado na Figura 15. Os casos foram simulados para o vento predominante de verão (nordeste) com velocidades de $1,0 \mathrm{~m} / \mathrm{s}, 3,0 \mathrm{~m} / \mathrm{s}$ e $6,0 \mathrm{~m} / \mathrm{s}$, sendo representados por círculos nas cores amarela, rosa e azul respectivamente.

Uma vez que ambientes com temperatura operativa superior a $25,0^{\circ} \mathrm{C}$ podem ter os limites da zona de conforto ampliados quando sujeitos à velocidade do ar acima de $0,3 \mathrm{~m} / \mathrm{s}$, foram consideradas as correções do limite superior da zona de conforto para velocidades do ar de $0,3 \mathrm{~m} / \mathrm{s} \leq 0,6 \mathrm{~m} / \mathrm{s}, 0,6 \mathrm{~m} / \mathrm{s} \leq 0,9 \mathrm{~m} / \mathrm{s} \mathrm{e} 0,9 \mathrm{~m} / \mathrm{s} \leq 1,2$ m/s (AMERICAN..., 2013).

As situações de conforto corrigido em decorrência de velocidades elevadas do ar são representadas pelas formas geométricas losango, quadrado e triângulo. O losango indica velocidades do ar entre $0,9 \mathrm{~m} / \mathrm{s}$ e 1,2 m/s, o quadrado entre $0,6 \mathrm{~m} / \mathrm{s}$ e $0,9 \mathrm{~m} / \mathrm{s}$, e o triângulo entre $0,3 \mathrm{~m} / \mathrm{s}$ e $0,6 \mathrm{~m} / \mathrm{s}$.

\section{Situações de desconforto}

A Figura 15 revela que, em um dia típico de verão, as temperaturas operativas sobre os usuários variam de $25,0^{\circ} \mathrm{C}$ a $30,0^{\circ} \mathrm{C}$. Um fator importante para a elevação do limite confortável da temperatura operativa é a velocidade do ar externo. Com o vento a $1,0 \mathrm{~m} / \mathrm{s}$, a temperatura operativa média sobre os usuários nos três quartos é de $28,4^{\circ} \mathrm{C}$. Ao elevar a velocidade do ar externo para 3,0 m/s e 6,0 m/s, esse valor se reduz para 27,3 ${ }^{\circ} \mathrm{C}$ e $26,4{ }^{\circ} \mathrm{C}$ respectivamente. 
Figura 14 - Velocidade do ar sobre cada usuário para o caso VC
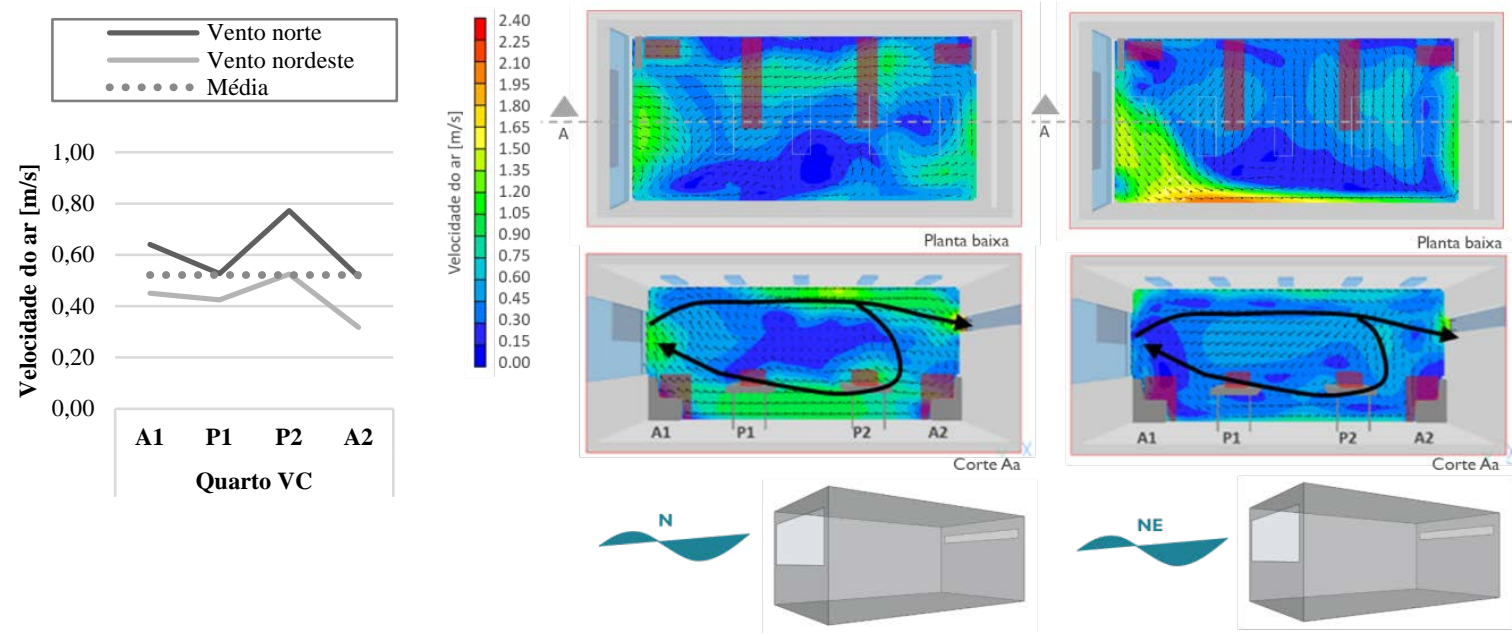

Observa-se que as temperaturas operativas mais elevadas ocorrem em condições de baixa velocidade do ar sobre os usuários $(<0,3 \mathrm{~m} / \mathrm{s})$. Por isso a maioria dos pontos amarelos foi destacada com um contorno vermelho, para destacar as situações que não atendem à norma ASHRAE Standard 55 (AMERICAN..., 2013). Esses resultados corroboram o estudo de Pires (2015), também realizado na cidade de Florianópolis, o qual conclui que movimentações do ar abaixo de $0,30 \mathrm{~m} / \mathrm{s}$ não são suficientes para auxiliar nas trocas de calor do indivíduo em um ambiente naturalmente ventilado no verão dessa cidade.

Outro aspecto determinante para o conforto térmico é a temperatura radiante, diretamente associada à temperatura operativa (FANGER; CHRISTENSEN, 1986). O posicionamento do usuário A1, mais próximo à parede externa, o expõe à incidência do ganho de calor por temperatura radiante da parede. Em todos os quartos, o A1 está em desconforto quando a velocidade do ar externo é de 1,0 m/s, resultando em temperaturas operativas entre $29,0^{\circ} \mathrm{C}$ e $30,0^{\circ} \mathrm{C}$.

\section{Situações de conforto}

Ainda com relação ao A1 apresentado na Figura 15, observam-se situações de correção do desconforto térmico proporcionado por velocidades do ar superiores a $0,3 \mathrm{~m} / \mathrm{s}$ nos casos VU2 e VC. Com o vento nordeste a 3,0 $\mathrm{m} / \mathrm{s}$ e a $6,0 \mathrm{~m} / \mathrm{s}$, a velocidade do ar sobre o A1 está entre $0,3 \mathrm{~m} / \mathrm{s}$ e $1,2 \mathrm{~m} / \mathrm{s}$ nos quartos com ventilação unilateral dupla e ventilação cruzada. Assim, apesar de esse usuário estar exposto às maiores temperaturas operativas, sua situação de desconforto é corrigida no quarto com ventilação unilateral dupla e no quarto com ventilação cruzada.

Os demais usuários, representados por P1, P2 e A2, apresentam temperaturas operativas médias de $26,1^{\circ} \mathrm{C}$, $27,2^{\circ} \mathrm{C}$ e $27,1^{\circ} \mathrm{C}$ respectivamente. Esses usuários encontram-se dentro da zona de conforto em um dia típico de verão com velocidade do ar externo igual ou superior a 3,0 m/s. A velocidade do ar se mostra como importante fator de correção da condição de desconforto.

Os casos de ventilação unilateral resultam em menores velocidades do ar interno, por isso em determinadas horas do dia o quarto deverá ter o apoio da ventilação mecânica ou do condicionamento artificial para o alcance do conforto térmico dos usuários. Sobre isso, Levin (2011) enfatiza a necessidade de apoio da ventilação mecânica ou do condicionamento artificial para edificações que possuam ventilação unilateral simples. Segundo Candido et al. (2010), usuários em climas quentes e úmidos apresentam significativa preferência pelo uso de ventiladores para temperaturas acima de $28{ }^{\circ} \mathrm{C}$.

De modo geral, observa-se a melhora das condições de conforto térmico do caso VU2 em relação ao caso VU1. Essa situação o coloca em uma posição comparável à do caso VC. Os estudos em túneis de vento de Chu et al. (2015) também revelaram melhora substancial do conforto térmico em um ambiente com ventilação unilateral dupla quando comparado ao mesmo ambiente com ventilação unilateral simples.

Essa situação enfatiza a importância do leiaute para o aproveitamento mais efetivo dos ventos predominantes, principalmente em ambientes hospitalares, por apresentarem pontos de instalações de gases medicinais que dificultam mudanças essenciais do leiaute para a garantia do conforto dos usuários. No caso VC, o desempenho 
da ventilação cruzada com o vento nordeste poderia ser otimizado caso os usuários estivessem na parede oposta.

Além do leiaute, outros recursos de projeto poderiam colaborar para o desempenho da ventilação unilateral. Segundo o Projeteee (2019), elementos de projeções horizontais e verticais do edifício podem ser utilizados de quatro formas para afetar o movimento do ar: aumentar o fluxo de entrada, interceptar e aumentar a admissão de brisas oblíquas, canalizar a direção da corrente dos fluxos de entrada e criar ventilação cruzada artificial. Esta última é possível de ser criada por meio de anteparos e aletas externas, também chamadas de wing-walls (DEKAY; BROWN, 2004).

\section{Conforto térmico na primavera}

Situações de desconforto térmico foram observadas no verão quando não há muita disponibilidade de ventos. Assim, foi necessária a investigação da efetividade da ventilação natural na primavera. Conforme apresentado anteriormente, o resultado do cálculo da temperatura média predominante para um dia típico da primavera em Florianópolis é de $16,8^{\circ} \mathrm{C}$, e o vento predominante é o norte.

A Figura 16 revela temperaturas operativas bem mais amenas do que os valores encontrados na situação de verão, conforme esperado, variando entre $20,0^{\circ} \mathrm{C}$ e $26,0{ }^{\circ} \mathrm{C}$ na área ocupada pelos usuários dos quartos de internação. Com o vento externo a $1,0 \mathrm{~m} / \mathrm{s}$, a temperatura operativa média nos três quartos é de $23,1^{\circ} \mathrm{C}$. Ao elevar a velocidade do ar externo para $3,0 \mathrm{~m} / \mathrm{s}$ e $6 \mathrm{~m} / \mathrm{s}$, esse valor se reduz para $21,9{ }^{\circ} \mathrm{C}$ e $21,2{ }^{\circ} \mathrm{C}$ respectivamente.

\section{Situações de desconforto}

Assim como no verão, as temperaturas operativas mais elevadas ocorrem sobre o A1. No entanto, na primavera esse usuário está em desconforto pelo calor apenas no caso VU1 exposto ao vento com velocidade de 1,0 m/s.

Figura 15 - Conforto adaptativo no verão com vento nordeste para os casos VU1, VU2 e VC

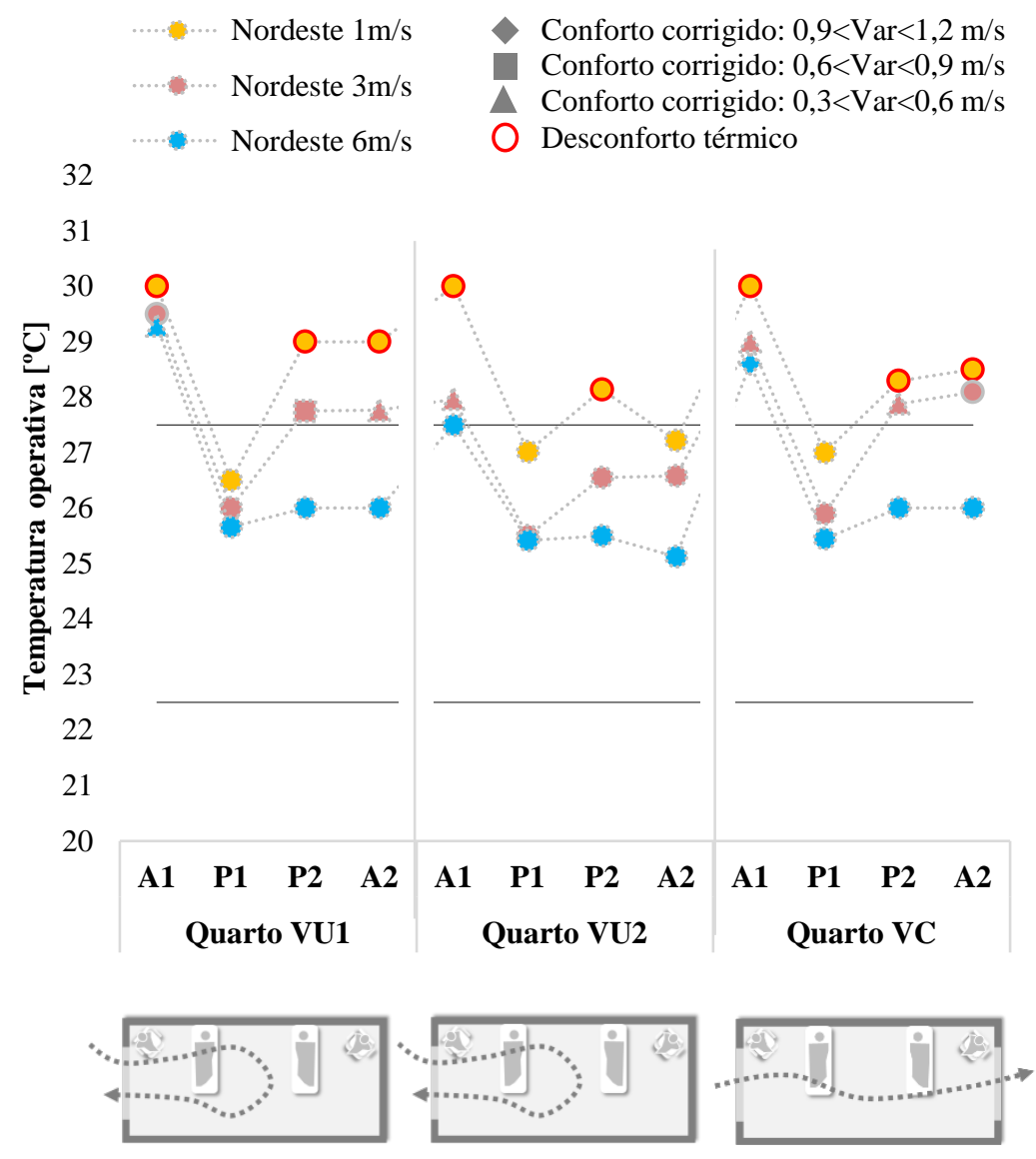


As demais condições de desconforto ocorrem pelo frio, mas podem ser facilmente controladas pelo fechamento da janela. No caso VU1 o P2 se aproxima do limite da zona de conforto com o vento norte a 6,0 m/s. No caso VU2, o P2 e o A2 já apresentam maior tendência a se sentirem insatisfeitos com o ambiente térmico com velocidades elevadas do ar externo.

Os asteriscos indicados no gráfico da Figura 14 destacam alguns usuários expostos à velocidade do ar superior a 1,2 m/s. Situações de desconforto localizado pela excessiva movimentação do ar são observadas para P1 (2,0 $\mathrm{m} / \mathrm{s}$ ) e P2 (1,4 m/s). A ASHRAE Standard 55 (AMERICAN..., 2013) fixa o limite superior em 0,8 m/s e 1,2 $\mathrm{m} / \mathrm{s}$ em espaços naturalmente ventilados sem e com mecanismos de controle (ventiladores, janelas operáveis, entre outros) respectivamente.

\section{Situações de conforto}

Na primavera a adoção das estratégias de ventilação cruzada e ventilação unilateral dupla é vantajosa por não apresentar desconforto por calor mesmo com pouca disponibilidade de ventilação natural. Tendo o usuário a possibilidade de operar as janelas com abertura máxima de $50 \%$ do vão, a ventilação natural nos quartos de internação atende às condições de conforto térmico dos pacientes e acompanhantes, sem a necessidade de uso de equipamentos de ventilação mecânica ou condicionamento artificial.

\section{Limitações do trabalho}

As principais limitações encontradas durante a realização desta pesquisa estão relacionadas à etapa de modelagem CFD que representam o comportamento do fluido em uma fração de tempo. Para isso a especificação das condições de contorno limitou as análises a um dia típico de verão e um dia típico de primavera.

Sabe-se que as velocidades e temperaturas do ar assumidas nos modelos de simulação são procedentes de estações meteorológicas afastadas dos centros urbanos em que estão localizados os hospitais. Nesses centros urbanos estão presentes aspectos modificadores dos ventos, como ilhas de calor, barreiras arquitetônicas e altura da edificação (LIMA; BITTENCOURT, 2017). No entanto, devido à falta de um coeficiente validado que defina essas mudanças para o contexto de Florianópolis, tais aspectos foram desconsiderados.

Com relação ainda aos parâmetros de entrada da simulação, para contemplar o efeito da radiação solar, o programa requer informações sobre o ganho de calor pelas paredes. Por essa razão foi necessário o cálculo estimativo do ganho de calor pela parede norte para a situação mais crítica. Diferentes condições de radiação solar poderiam modificar os resultados.

No âmbito da análise de conforto térmico há uma lacuna no conhecimento sobre esse conforto em pessoas com saúde fragilizada. Estudos encontrados não especificam uma faixa de conforto para pessoas doentes, mas apontam uma preferência por temperaturas levemente mais altas. Assim, devido à falta de informações conclusivas, nesta pesquisa foram utilizados os limites de faixa de conforto para adultos saudáveis.

\section{Conclusões}

Este trabalho teve como foco a análise do desempenho da ventilação natural sobre o conforto térmico dos usuários para três tipologias de quartos de internação hospitalar: com ventilação unilateral simples (VU1), com ventilação unilateral dupla (VU2) e com ventilação cruzada em paredes opostas (VC). Todos os quartos possuíam janelas de correr com abertura máxima de 50\% da área do vão.

As temperaturas operativas, as velocidades do ar e o fluxo de ar em um mesmo quarto se mostraram bastante heterogêneos, e, consequentemente, foram observadas diferenças importantes nas condições térmicas dos usuários de um mesmo ambiente.

Os resultados encontrados referentes à análise do conforto térmico revelam maior eficiência do vento norte (ângulo de incidência de $0^{\circ}$ em relação à normal da fachada) em relação ao vento nordeste (ângulo de incidência $45^{\circ}$ em relação à normal da fachada), principalmente na condição de primavera, em que as temperaturas externas são mais amenas. Apesar de a velocidade do ar ser a mesma, a pressão exercida pelo vento norte sobre a fachada da edificação é maior, resultando em um campo com maior diferencial de pressão e valores superiores de velocidade do ar interno. 
Figura 16 - Conforto adaptativo na primavera com vento norte para os casos VU1, VU2 e VC

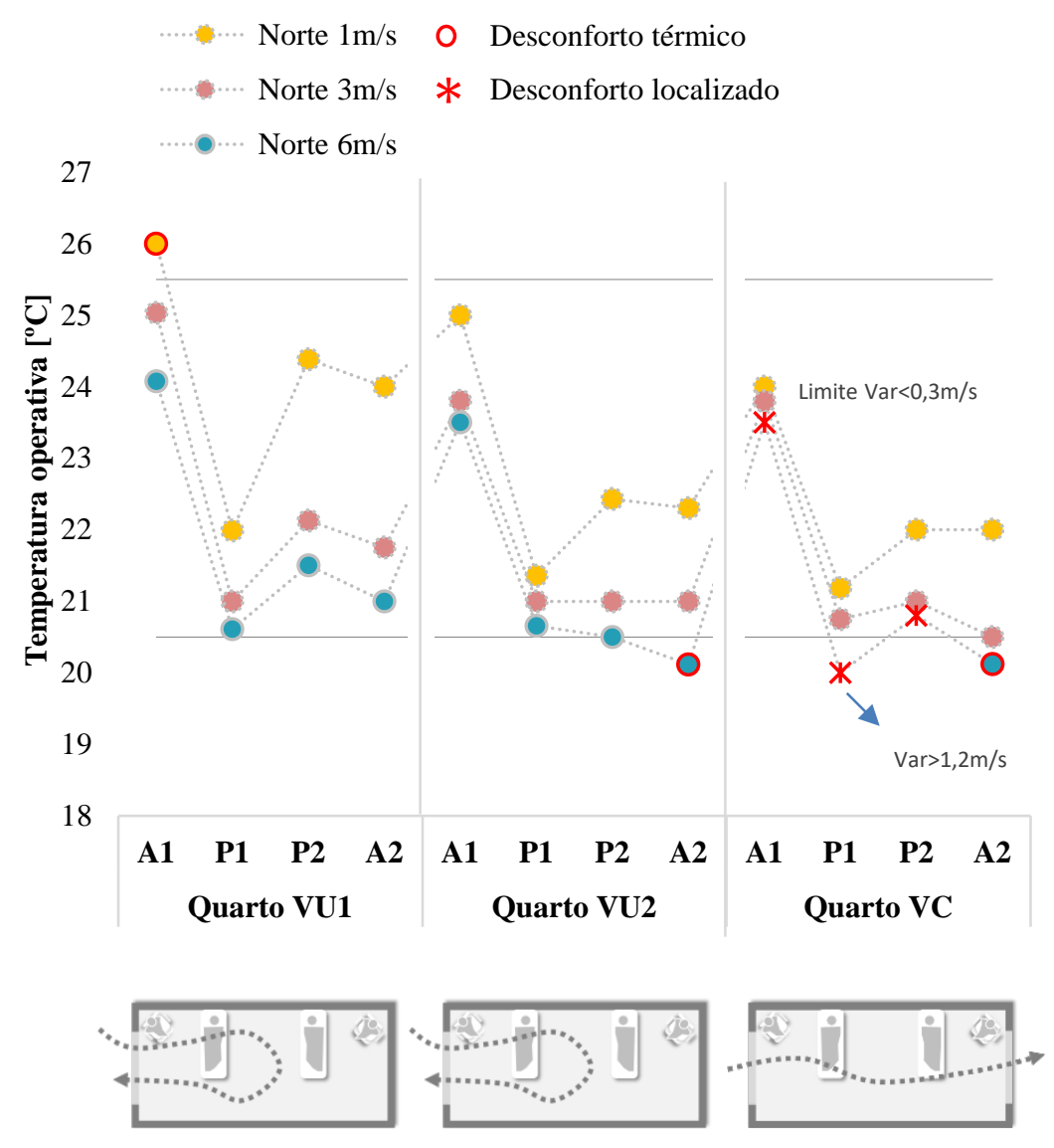

Então, destaca-se a importância da concepção inicial de projeto privilegiando os ventos perpendiculares às principais aberturas da edificação para melhor aproveitamento da ventilação natural disponível na temporada de primavera. No caso da impossibilidade de orientar as aberturas diretamente para os ventos dominantes, podem ser criadas zonas de pressão positiva e negativa por meio do projeto de elementos externos, como vegetação e projeções na parede. Esses elementos redirecionam a ventilação para a abertura de interesse.

Verificou-se ainda que ventos de até $1,0 \mathrm{~m} / \mathrm{s}$ são insuficientes para corrigir o desconforto por calor em um dia típico de verão apenas com o uso da ventilação natural, sendo então importante a adoção de estratégias complementares de ventilação híbrida, que alterna o uso da ventilação natural com sistemas de condicionamento artificial ou de sistemas mecânicos, como o uso de ventilador de teto.

A ventilação natural favorece o conforto térmico nos quartos com ventilação unilateral dupla e ventilação cruzada nas situações recorrentes de ventos norte e nordeste acima de 1,0 m/s em um dia típico de verão em Florianópolis. A ventilação unilateral simples, por sua vez, apresenta um desempenho satisfatório apenas na primavera, quando a temperatura do ar é considerada aceitável e não requer elevadas velocidades do ar.

Em ambos os períodos o controle das aberturas é essencial para evitar ventos indesejados. Na primavera, o controle das aberturas deve ser utilizado para reduzir a ação dos ventos externos com velocidade a partir de 3,0 m/s, enquanto no período de verão elas devem ser mantidas abertas para a circulação do ar. Ressalta-se que a possibilidade de operação das aberturas também auxilia no controle de outros fatores ambientais, como ruídos externos e chuvas.

Os resultados desta pesquisa apontam um melhor desempenho das estratégias de ventilação unilateral dupla e ventilação cruzada em comparação à ventilação unilateral simples, amplamente utilizada em quartos de internação. Todavia, como a tendência de hospitais verticalizados e densos dificulta a adoção da ventilação cruzada, a ventilação unilateral dupla aparece como a alternativa mais viável para o conforto térmico em ambientes de internação. 
A partir das conclusões apontadas, foram elaboradas diretrizes para o projeto de ambientes de internação hospitalar naturalmente ventilados:

(a) privilegiar o posicionamento dos quartos de internação nas fachadas com ângulo de incidência mais próximo de $0^{\circ}$ em relação à normal da fachada;

(b) privilegiar o uso de tipologias arquitetônicas que possibilitem a ventilação cruzada;

(c) adotar a ventilação unilateral dupla como alternativa mais eficiente que a ventilação unilateral simples;

(d) considerar no leiaute o alinhamento entre os leitos e a abertura efetiva das janelas para melhor aproveitamento do fluxo de ar de entrada;

(e) avaliar condições climáticas e prever o uso auxiliar de ventilador de teto ou de ar-condicionado quando forem observadas condições de ventos frequentes abaixo de $1,0 \mathrm{~m} / \mathrm{s}$; e

(f) facilitar a operacionalidade das janelas (abertura e fechamento) para evitar ventos indesejados nos períodos mais amenos.

De forma a complementar a área do conhecimento, futuros trabalhos sobre o assunto poderiam investigar a aplicabilidade do modelo adaptativo de análise de conforto térmico para pacientes em quartos de internação naturalmente condicionados em Florianópolis. Outra possibilidade seria investigar o desempenho de diferentes tipos de esquadrias em quartos de internação, variando tamanho, posição e sistema de abertura. Variações também poderiam ser feitas quanto às dimensões e ao pavimento do quarto.

\section{Referências}

ADAMU, Z. A.; PRICE, A. D. F.; COOK, M. J. Performance evaluation of natural ventilation strategies for hospital wards: a case study of Great Ormond Street Hospital. Building and Environment, v. 56, p. 211222, 2012.

AFLAKI, A.; MAHYUDDIN, N.; BAHARUM, M. R. The influence of single-sided ventilation towards the indoor thermal performance of high-rise residential building: a field study. Energy and Buildings, v. 126, p. 146-158, 2016.

AGÊNCIA NACIONAL DE VIGILÂNCIA SANITÁRIA. RDC n. 50, de 21 de fevereiro de 2002, que dispõe sobre o regulamento técnico para planejamento, programação, elaboração e avaliação de projetos físicos de estabelecimentos assistenciais de saúde. Brasília, 2002.

ALLOCCA, C.; CHEN, Q.; GLICKSMAN, L. R. Design analysis of single-sided natural ventilation. Energy and Buildings, v. 35, n. 8, p. 785-795, 2003.

AMERICAN SOCIETY OF HEATING, REFRIGERATING AND AIR CONDITIONING ENGINEERS. Standard 55: thermal environmental conditions for human occupancy. Atlanta, 2013.

ASSOCIAÇÃO BRASILEIRA DE NORMAS TÉCNICAS. NBR 15220-2: desempenho térmico de edificações: parte 2: métodos de cálculo da transmitância térmica, da capacidade térmica, do atraso térmico e do fator solar de elementos e componentes de edificações. Rio de Janeiro, 2005.

AYATA, T.; YILDIZ, O. Investigating the potential use of natural ventilation in new building designs in Turkey. Energy and Buildings, v. 38, n. 8, p. 959-963, 2006.

BASKARAN, A.; KASHEF, A. Investigação do fluxo de ar em torno de edifícios usando dinâmica de fluidos computacional. Engineering Structures, v. 18, n. 11, p. 861-875, 1996.

BRASIL. MINISTÉRIO DA SAÚDE. SomaSUS: Sistema de Apoio à Elaboração de Projetos de Investimentos em Saúde. Brasília, 2013.

CANDIDO, C. et al. Aplicabilidade dos limites da velocidade do ar para efeito de conforto térmico em climas quentes e úmidos. Ambiente Construído, Porto Alegre, v. 10, p. 59-68, 2010.

CANDIDO, C.; BITTENCOURT, L. Introdução à ventilação natural. Maceió: Edufal, 2006.

CHENARI, B.; DIAS CARRILHO, J.; GAMEIRO DA SILVA, M. Towards sustainable, energy-efficient and healthy ventilation strategies in buildings: a review. Renewable and Sustainable Energy Reviews, v. 59, p. 1426-1447, 2016.

CHU, C. R. et al. Wind-driven natural ventilation for buildings with two openings on the same external wall. Energy and Buildings, v. 108, p. 365-372, 2015. 
DE DEAR, R. J.; BRAGER, G. S. Thermal comfort in naturally ventilated buildings: revisions to ASHRAE Standard 55. Energy and Buildings, v. 34, n. 6, p. 549-561, 2002.

DEKAY, M.; BROWN, G. Z. Sol, vento e luz: estratégias para o projeto de arquitetura. 2. ed. Porto Alegre: Bookman, 2004.

DILANI, A. Psychosocially supportive design: as a theory and model to promote health. In: WORLD CONGRESS AND EXHIBITION FOR DESIGN AND HEALTH, Stockhom, 2005. Proceedings [...] Stockholm, 2005.

ESCOMBE, A. R. et al. Natural ventilation for the prevention of airborne contagion. PLoS Medicine, v. 4, n. 2, p. e68, 2007.

FANGER, P.; CHRISTENSEN, N. Perception of draught in ventilated spaces. Ergonomics, v. 29, n. 2, p. 215-235, 1986.

FOUCAULT, M. Microfísica do poder. Rio de Janeiro: GRAAL, 1979.

GÓES, R. Manual prático de arquitetura hospitalar. São Paulo: Edgar Blucher, 2004.

GONZÁLEZ C, E. M. Comportamiento térmico de edificaciones. Tabla: Cálculo de la Temperatura Media Interior en Región Caliente. Maracaibo, 2013.

HOYT, T. et al. CBE Thermal Comfort Tool. Center for the Built Environment, University of California Berkeley 2012-2014. Disponível em: http://comfort.cbe.berkeley.edu. Acesso em: 20 jun. 2018.

INSTITUTO NACIONAL DE METROLOGIA, QUALIDADE E TECONOLOGIA. Portaria INMETRO/MDIC n. 372, de 17 de setembro de 2010. Aprovar a revisão dos Requisitos Técnicos da Qualidade para o Nível de Eficiência Energética de Edifícios Comerciais, de Serviços e Públicos (RTQ). 2010.

JONES, J.; WEST, A. Natural ventilation and collaborative design. ASHRAE Journal, v. 43, n. 11, p. 4651, 2001.

KOLOKOTRONI, M. Ventilation for cooling. In: SANTAMOURIS, M. (Ed.). Advances in passive cooling. London: Earthscan, 2007.

LEVIN, H. Natural ventilation: a sustainable solution to infection control in healthcare settings? In: IAQ CONFERENCE, 2011. Proceedings [...] Santa Cruz, 2011.

LIMA, R. G.; BITTENCOURT, L. S. A influência de diferentes arranjos construtivos no comportamento da ventilação natural. Revista Brasileira de Gestão Urbana, v. 9, n. 1, p. 425-441, 2017.

LOMAS, K. J.; JI, Y. Resilience of naturally ventilated buildings to climate change: Advanced natural ventilation and hospital wards. Energy and Buildings, v. 41, n. 6, p. 629-653, 2009.

LUKIANTCHUKI, M. A. A evolução das estratégias de conforto térmico e ventilação natural na obra de João Filgueiras Lima, Lelé: Hospitais Sarah Salvador e Rio de Janeiro. São Carlos, 2010. 320 f. Dissertação (Mestrado em Engenharia Civil) - Escola de Engenharia de São Carlos, Universidade de São Paulo, São Carlos, 2010.

MIQUELIN, L. C. Morfologia dos edifícios hospitalares. São Paulo: CEDAS, 1992.

NATIONAL RENEWABLE ENERGY LABORATORY. SWERA. 2011. Disponível em: https://maps.nrel.gov/swera. Acesso em: 12 mar. 2019.

ORGANIZAÇÃO MUNDIAL DA SAÚDE. Natural ventilation for infection control in health-care settings. Switzerland, 2009.

PIRES, M. O. Conforto térmico em ambientes de escritórios naturalmente condicionados: pesquisa de campo na cidade de Florianópolis por meio da abordagem adaptativa. Florianópolis, 2015. Dissertação (Mestrado em Engenharia Civil) - Programa de Pós-graduação em Arquitetura e Urbanismo, Universidade Federal de Santa Catarina, Florianópolis, 2015.

PRAJONGSAN, P.; SHARPLES, S. Enhancing natural ventilation, thermal comfort and energy savings in high-rise residential buildings in Bangkok through the use of ventilation shafts. Building and Environment, v. 50, p. 104-113, 2012.

PROJETEEE. Projetando edificações energeticamente eficientes: estratégias bioclimáticas. 2019.

Disponível em: http://projeteee.mma.gov.br/estrategias-bioclimaticas. Acesso em: 13 mar. 2019. 
RUPP, R. F.; VÁZQUEZ, N. G.; LAMBERTS, R. A review of human thermal comfort in the built environment. Energy and Buildings, v. 105, p. 178-205, 2015.

SALONEN, H. et al. Physical characteristics of the indoor environment that affect health and wellbeing in healthcare facilities: a review. Intelligent Buildings International, v. 5, n. 1, p. 1-50, 2013.

SCHULZE, T.; EICKER, U. Controlled natural ventilation for energy efficient buildings. Energy and Buildings, v. 56, p. 221-232, 2013.

SOUTULLO, S. et al. Thermal comfort evaluation in a mechanically ventilated office building located in a continental climate. Energy and Buildings, v. 81, p. 424-429, 2014.

SPALDING, D. B. The Phoenics Encyclopedia. Londres: CHAM Ltd, 1994

STABAT, P.; CACIOLO, M.; MARCHIO, D. Progress on single-sided ventilation techniques for buildings. Advances in Building Energy Research, v. 6, n. 2, p. 212-241, 2012.

TOLEDO, L. C. Feitos para curar: arquitetura hospitalar e o processo projetual no Brasil. Rio de Janeiro: ABDEH, 2006.

ULRICH, R. et al. The role of the physical environment in the hospital of the 21st Century: a once-in-alifetime opportunity. Concord, 2004. [Relatório para The Center of Health Design].

ZHAI, Z. Application of computational fluid dynamics in building design: aspects and trends. Indoor and Built Environment, v. 15, n. 4, p. 305-313, 2006.

\section{Bianca Milani de Quadros}

Departamento de Arquitetura e Urbanismo | Universidade do Sul de Santa Catarina | Rua Antônio Dib Mussi, 366, Centro | Florianópolis SC - Brasil | CEP 88015-110 | Tel.: (48) 3279-0975 | E-mail: bianca.quadros@unisul.br

\section{Martin Ordenes Mizgier}

Departamento de Arquitetura e Urbanismo | Universidade Federal de Santa Catarina | Campus Universitário, Trindade | Caixa Postal 476 | Florianópolis - SC - Brasil | CEP 88040-900 | Tel.: (48) 3721-4961 | E-mail: martin.ordenes@ufsc.br

\section{Ambiente Construído}

Revista da Associação Nacional de Tecnologia do Ambiente Construído

Av. Osvaldo Aranha, 99 - 3o andar, Centro

Porto Alegre - RS - Brasil CEP $90035-190$

Telefone: +55 (51) 3308-4084

Fax: +55 (51) 3308-4054

www. seer. ufrgs. br/ ambienteconstruido

E-mail: ambienteconstruido@ufrgs.br 